\title{
Optimization of the octane response of gasoline/ethanol blends
}

\author{
Jihad Badra $^{\mathrm{a}, *}$, Abdullah S. AlRamadan ${ }^{\mathrm{a}, \mathrm{b}, *}$, S. Mani Sarathy ${ }^{\mathrm{b}}$ \\ a Saudi Aramco Research and Development Center, Fuel Technology RED Division, Dhahran 31311, Saudi Arabia \\ ${ }^{\mathrm{b}}$ King Abdullah University of Science and Technology (KAUST), Clean Combustion Research Center, Thuwal 23955, Saudi Arabia
}

\section{H I G H L I G H T S}

- New experimental data for five components with ethanol addition are collected.

- A new blending rule for PRF, TPRF and multi-components + ethanol octane numbers is proposed.

- The developed model is validated against real gasoline fuel data.

- Methods to optimize the octane response due to ethanol addition are proposed.

\section{A R T I C L E I N F O}

\section{Article history:}

Received 4 January 2017

Received in revised form 22 June 2017

Accepted 28 June 2017

\section{Keywords}

Ethanol

Octane responses

FACE gasoline

Multi-component

Ethanol

\begin{abstract}
A B S T R A C T
The octane responses of gasoline/ethanol mixtures are not well understood because of the unidentified intermolecular interactions in such blends. In general, when ethanol is blended with gasoline, the Research Octane Number (RON) and the Motor Octane Number (MON) non-linearly increase or decrease, and the non-linearity is determined by the composition of the base gasoline and the amount of added ethanol. The complexity of commercial gasolines, comprising of hundreds of different components, makes it challenging to understand ethanol-gasoline synergistic/antagonistic blending effects. Understanding ethanol blending effects with simpler gasoline surrogates is critical to acquire knowledge about ethanol blending with complex multi-component gasoline fuels. In this study, the octane numbers $(\mathrm{ON})$ of ethanol blends with five relevant gasoline surrogate molecules were measured. The molecules investigated in this study include: n-pentane, iso-pentane, 1,2,4-trimethylbenzene, cyclopentane and 1 -hexene. These new measurements along with the available data of n-heptane, iso-octane, toluene, various primary reference fuels (PRF) and toluene primary reference fuels (TPRF) with ethanol are used to develop a blending rule for the octane response (RON and MON) of multi-component blends with ethanol. In addition, new ON data are collected for six Fuels for Advanced Combustion Engine (FACE) with ethanol. The relatively simple volume based model successfully predicts the octane numbers (ON) of the various ethanol/PRF and ethanol/TPRF blends with the majority of predictions being within the ASTM D2699 (RON) and D2700 (MON) reproducibility limits. The model is also successfully validated against the ON of the FACE gasolines blended with ethanol with the majority of predictions being within the reproducibility limits. Finally, insights into the possible causes of the synergistic and antagonistic effects of different molecules with ethanol are provided.
\end{abstract}

(c) 2017 Elsevier Ltd. All rights reserved.

\section{Introduction}

Ethanol is the most widely used biofuel and blending agent for commercial gasoline fuels [1,2]. A key benefit of ethanol blending is the ability to meet the demand for higher octane RON numbers in modern downsized spark ignition (SI) engines [3,4]. Higher

\footnotetext{
* Corresponding authors at: P.O. Box 62, Dhahran, Eastern province 31311, Saudi Arabia (J. Badra). Thuwal, Mekkah Province 23955, Saudi Arabia (A.S. AlRamadan).

E-mail addresses: jihad.badra@aramco.com (J. Badra), abdullah.alramadan@ kaust.edu.sa (A.S. AlRamadan).
}

octane numbers allow engine operations at higher compression ratios and hence greater thermal efficiencies [5-8]. When ethanol is added to the fuel, it burns in a cleaner manner and releases fewer regulated emissions in comparison to pure gasoline [9-14]. The US Energy Independence and Security Act (EISA) of 2007 [15] endorsed a mandatory target to increase the transportation renewable fuel use from 9 billion gallons in 2008 to 36 billion gallons by 2022. Along the same lines, the European Council in March 2007 [16] mandated all EU member countries to have at least $10 \mathrm{vol} \%$ biofuels in the transportation fuel by 2020 . 


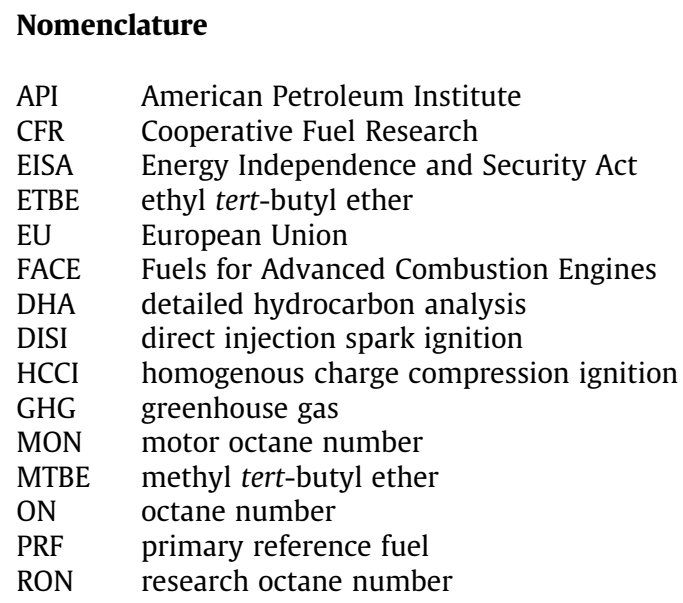

$\begin{array}{ll}\text { SI } & \text { spark ignition } \\ \text { TPRF } & \text { toluene primary reference fuel } \\ \text { US } & \text { United States } \\ & \\ \text { Symbols } & \\ \alpha & \text { scaling factor } \\ \text { D } & \text { difference factor } \\ \varnothing & \text { volume fraction }\end{array}$

$\begin{array}{ll}\text { Subscripts } \\ \text { eth } & \text { ethanol } \\ \text { Mix } & \text { mixture } \\ \text { I,T } & \text { iso-octane and toluene } \\ \text { H,T } & \text { n-heptane and toluene }\end{array}$

Because of the relevance of ethanol, many previous works have investigated the emissions offset by blending ethanol into gasoline and/or the effect of ethanol on engine performance [3,4,17-28]. Today, the ethanol fuel that is available in the market is mainly made from sugar cane or corn [29-33]. Its production as a firstgeneration biofuel, especially in North America, has been associated with publicly discussed drawbacks, such as reduction in the food supply, need for fertilization, extensive water usage, and other ecological concerns. More environmentally friendly processes are being considered to produce alcohols from inedible plants or plant parts on wasteland [34].

Ethanol has higher octane ratings compared to regular gasoline [35]. Engine knock is one of the limiting factors inhibiting spark ignition (SI) engines from achieving higher thermal efficiencies. Higher octane fuels, such as ethanol, can enable more efficient SI engine technologies. A chief motivation of the present work is to develop models that predict how ethanol blending increases the octane number of a gasoline blendstock. This information can be useful for designing fuel formulations which offer higher engine efficiency while potentially leading to a net lifecycle greenhouse gas (GHG) emissions reductions [24,36].

\section{Background}

This section summarizes the literature on ethanol's antiknock quality, knocking in engines, blending effects, and gasoline fuels.

Sarathy et al. [37] attributed ethanol's high antiknock quality to its lack of low-temperature ignition reactivity, wherein ethanol favors chain termination pathways leading to the formation of acetaldehyde and hydroperoxy radicals over conventional hydroxyl radical chain branching pathways. In addition, the high latent heat of vaporization of ethanol reduces the charge-gas temperature when directly injected, which in turn delays the autoignition $[6,7]$. This feature is commonly known as the charge cooling effect. However, ethanol has lower heating value than gasoline, resulting in a lower energy content per unit volume [10]. Another interesting application of alcohols (methanol and ethanol) is the newly studied octane-on-demand technology where the alcohols are used as the high octane fuels enabling the achievement of higher thermal efficiencies and lower GHG emissions [9-11]. In addition, butanol isomers might also be good octane booster candidates with higher energy density compared to methanol and ethanol. We recently investigated the ignition delay times of mixed butanols/TPRF surrogates [38].
Engine knock is known as the metallic ringing noise caused by the autoignition of the unburned air/fuel mixture ahead of the propagating flame front $[39,40]$. This autoignition phenomenon generates pressure waves, which can cause severe damage to the engine's hardware [41]. The fuel's tendency to autoignite is described by two parameters known as research octane number (RON) and motor octane number (MON), whose specifications are defined in ASTM D2699 [42] and ASTM D2700 [43], respectively. It is established that the RON of a regular gasoline increases with ethanol addition, but the extent of the increase is still not fully understood yet. Recently, AlRamadan et al. [44] and Yuan et al. [45] proposed molar based blending rules for predicting the octane response of toluene primary reference fuels (TPRF) mixtures with ethanol. Hunwartzen [46] reported a linear by volume increase of the RON with ethanol addition to gasoline, which has been contradicted by an American Petroleum Institute (API) study [47] and Anderson et al. [27]. Anderson et al. [27] reported that the ON (RON and MON) increase follows a linear by mole response for gasoline fuels with certain compositions when blended with ethanol and methanol. They have also investigated the ON response due to the addition of other alcohols (iso-butanol) and ethers (methyl tert-butyl ether (MTBE) and ethyl tert-butyl ether (ETBE)). Recently, Anderson et al. [48], Foong et al. [49] and Aronsson et al. [50] reported non-linear by volume and non-linear by mole increases of RON when ethanol is blended with gasoline, suggesting a synergistic effect (a further increase from the linear volume or molar model). The reported synergistic effect depends on the composition of the base fuel. For ethanol blending to gasoline at the MON condition, a linear by mole response was proposed by Anderson et al. [27], synergistic increases were reported by Foong et al. [49] and Anderson et al. [48] and antagonistic effects (a decrease from the linear volume or molar model) were reported by Hunwartzen [46] and Foong et al. [49]. The aforementioned discrepancies can likely be attributed to the specific distribution of paraffins, iso-paraffins, olefins, naphthenes, and aromatics in the base gasolines that they used. Briefly, the composition of the base gasoline plays a major role in predicting the RON and MON of ethanol blends with gasoline.

The present work first focuses on studying the effect of ethanol blending with eight pure components, namely, n-pentane, n-heptane, iso-pentane, iso-octane, toluene, 1,2,4trimethylbenzene, cyclopentane and 1-hexene. These species were selected in a systematic way so they cover the classes of molecules (n-paraffins, iso-paraffins, aromatics, naphthenes and olefins) relevant to gasoline fuels, in particular the Fuels for Advanced 
Combustion Engines (FACE) gasolines [51], which are also studied herein. The aforementioned molecules have been proposed as palette species for surrogate mixtures of the FACE gasolines [52]. A series of studies on FACE gasolines have been published in recent years. Their fundamental combustion kinetics has been explored in shock tubes, rapid compression machines, jet stirred reactors, and premixed flames [52-56] Furthermore, engine studies have been performed to assess FACE gasoline combustion characteristics under homogenous charge compression ignition (HCCI) [57], direct inject spark ignition (DISI) [58] and blending effects on SI engine antiknock quality when using various biofuels [59]. The selected surrogate palette species have been subjected to rigorous chemical kinetic modeling studies, including recent state-of-the-art models for n-pentane [60,61], n-heptane [62], iso-pentane [60,61], isooctane [63], toluene [64], 1,2,4-trimethylbenzene [52], cyclopentane [65-67] and 1-hexene [68,69].

In this work, a non-linear by volume blending model is developed to predict the octane response of ethanol addition to individual gasoline surrogate palette molecules and multi-component gasoline surrogate mixtures. The model is validated against a wide range of octane numbers for various primary reference fuels (PRFs), toluene primary reference fuels (n-heptane/iso-octane/toluene fuels (TPRFs)) and FACE gasoline fuels.

\section{RON and MON measurements for pure components and FACE gasolines blended with ethanol}

\subsection{Experimental methodology}

Octane numbers (RON and MON) data are available in literature for blends of ethanol with n-heptane [49], iso-octane [49], toluene [49], PRF [44,49] and TPRF [44,49]. Based on these data, AlRamadan et al. [44] developed a molar based blending rule for PRF and TPRF mixtures with ethanol. To extend that model to include more molecules relevant to gasoline surrogates, new RON and MON measurements were obtained for five additional single components with ethanol. The examined components were chosen based on the different classes of molecules relevant to gasoline surrogates. The $\mathrm{ON}$ of $\mathrm{n}$-pentane (n-paraffinic), iso-pentane (iso-paraffinic), 1,2,4-trimethylbenzene (aromatics), cyclopentane (naphthenes) and 1-hexene (olefins) blended with multiple volume fractions (0-60 vol\%) of ethanol were measured here following the standard test methods for RON and MON [42,43] using the Saudi Aramco Cooperative Fuel Research (CFR) engine facility. The differences between the ethanol and gasoline physical chemical properties introduce some challenges in the hardware used to measure the RON and MON [42,43]. Ethanol has lower stoichiometric air/fuel ratio compared to gasoline, and hence the standard fuel metering jet for RON and MON tests is inappropriate to supply sufficient fuel flow rate of ethanol [46]. German institute for standardization DIN 51756-7 [70] suggests some modifications to the engine hardware to measure fuels with high alcoholic content. Replacing the original carburetor jet by an adjustable orifice jet to supply sufficient flow rate of alcohol for both the RON and MON tests is one of the recommendations. This hardware modification has been implemented in this study to ensure sufficient flow rate of ethanol-rich fuels.

In addition, the high heat of vaporization of ethanol $[27,43,49]$ introduces difficulties in maintaining the standard temperatures of the fuel/air mixtures in the RON and MON conditions. An external electric heating system is suggested to be used in the MON test to provide additional heat to compensate for the cooling effect of the ethanol-rich air/fuel mixture. At RON conditions, Foong et al. [49] proposed modifications to the CFR engine to measure RON of ethanol-containing mixtures. They reported standard and modified RON measurements for various ethanol/PRF mixtures and noted that differences up to 4 points can be observed between the standard and modified RON. However, the RON and MON measurements reported in this work are from a standard CFR engine without modifications in the RON test conditions. The ON of pure ethanol in this study are taken from Foong et al. [49] (RON 108, MON 90.7), where they followed the recommendations discussed earlier $[42,43,70]$.

With these new RON and MON measurements, gasoline surrogate mixtures can be formulated using multiple species within a certain hydrocarbon class (as opposed to conventional PRF and TPRF surrogates). For example, n-heptane and n-pentane are available to represent the n-paraffinic class. Similarly, iso-octane and iso-pentane for the iso-paraffinic class, and toluene and 1,2,4-trimethylbenzene for the aromatic classes. In addition, representatives of the naphthenes (cyclopentane) and olefins (1hexene) are now accessible when formulating surrogates for gasoline fuels.

In addition, six FACE gasolines were blended with ethanol, and their RON and MON were measured to validate the developed blending rule. The FACE gasolines were chosen based on their different compositions. For example, FACE A, C and I were chosen because of their high paraffinic contents ( $\sim 90 \mathrm{vol} \%$ ). FACE G and J have high aromatic contents (>30 vol\%). Finally, FACE F was selected because of its considerable amounts of naphthenes ( $\sim 10 \mathrm{vol} \%$ ) and olefins ( $\sim 10 \mathrm{vol} \%)$. In addition, these FACE gasolines were chosen because some pairs have comparable RON and MON values but different compositions. FACE A and $C$ have similar RON and MON despite the differences in the compositions. The same applies to FACE F and G and to FACE I and J. The compositions and properties of the studied FACE gasolines are listed in Table 1. More details about the FACE gasolines can be found in [51].

\subsection{Experimental results}

Table 2 summarizes the new CFR engine measurements for the five single components blended with ethanol. These volume and mole based experimental data are presented in Fig. 1 and Fig. 2. The calculated RON and MON using the linear-by-volume or mole method are also shown in Fig. 1 and Fig. 2, respectively. Regarding the volume based experimental data, it is clearly seen from Fig. 1

Table 1

Compositions and the octane ratings of the six tested FACE gasolines. The data are taken from [51].

\begin{tabular}{|c|c|c|c|c|c|c|}
\hline & \multicolumn{6}{|c|}{ FACE } \\
\hline & A & C & $\mathrm{F}$ & G & I & $\mathrm{J}$ \\
\hline RON & 83.5 & 84.7 & 94.4 & 96.8 & 70.3 & 71.8 \\
\hline MON & 83.6 & 83.6 & 88.8 & 85.8 & 69.6 & 68.8 \\
\hline n-Paraffins (vol\%) & 11.7 & 24.4 & 4.4 & 6.8 & 14.5 & 31.6 \\
\hline iso-Paraffins (vol\%) & 86.0 & 69.7 & 67.5 & 39.0 & 74.6 & 33.7 \\
\hline Aromatics (vol\%) & 0.7 & 3.9 & 7.7 & 34.2 & 1.2 & 31.8 \\
\hline Naphthenes & 1.6 & 0.7 & 11.0 & 11.7 & 3.3 & 2.3 \\
\hline Olefins & 0.0 & 1.3 & 9.4 & 8.3 & 6.4 & 0.6 \\
\hline
\end{tabular}


Table 2

Measured RONs and MONs of different single components blended with ethanol.

\begin{tabular}{|c|c|c|c|c|c|c|c|c|c|c|}
\hline \multirow[b]{2}{*}{ Ethanol vol\% } & \multicolumn{2}{|c|}{ n-Pentane } & \multicolumn{2}{|c|}{ iso-Pentane } & \multicolumn{2}{|c|}{ 1,2,4-Trimethylbenzene } & \multicolumn{2}{|c|}{ Cyclopentane } & \multicolumn{2}{|c|}{ 1-Hexene } \\
\hline & RON & MON & RON & MON & RON & MON & RON & MON & RON & MON \\
\hline 0 & 61.7 & 58.3 & 92.0 & 90.0 & 109.5 & 108.0 & 100.0 & 85.6 & 73.6 & 64.5 \\
\hline 10 & 72.0 & 66.0 & 95.5 & 91.0 & 107.0 & 102.0 & 101.0 & 85.9 & 81.0 & 68.5 \\
\hline 25 & 83.2 & 78.2 & 100.0 & 92.0 & 105.0 & 95.5 & 102.3 & 86.3 & 89.2 & 74.5 \\
\hline 40 & 93.6 & 86.0 & 102.4 & 92.6 & 104.0 & 93.5 & 103.3 & 86.6 & 96.5 & 79.5 \\
\hline 60 & 103.4 & 92.8 & 105.5 & 92.7 & 105.8 & 91.0 & 104.8 & 87.2 & 101.7 & 84.0 \\
\hline
\end{tabular}
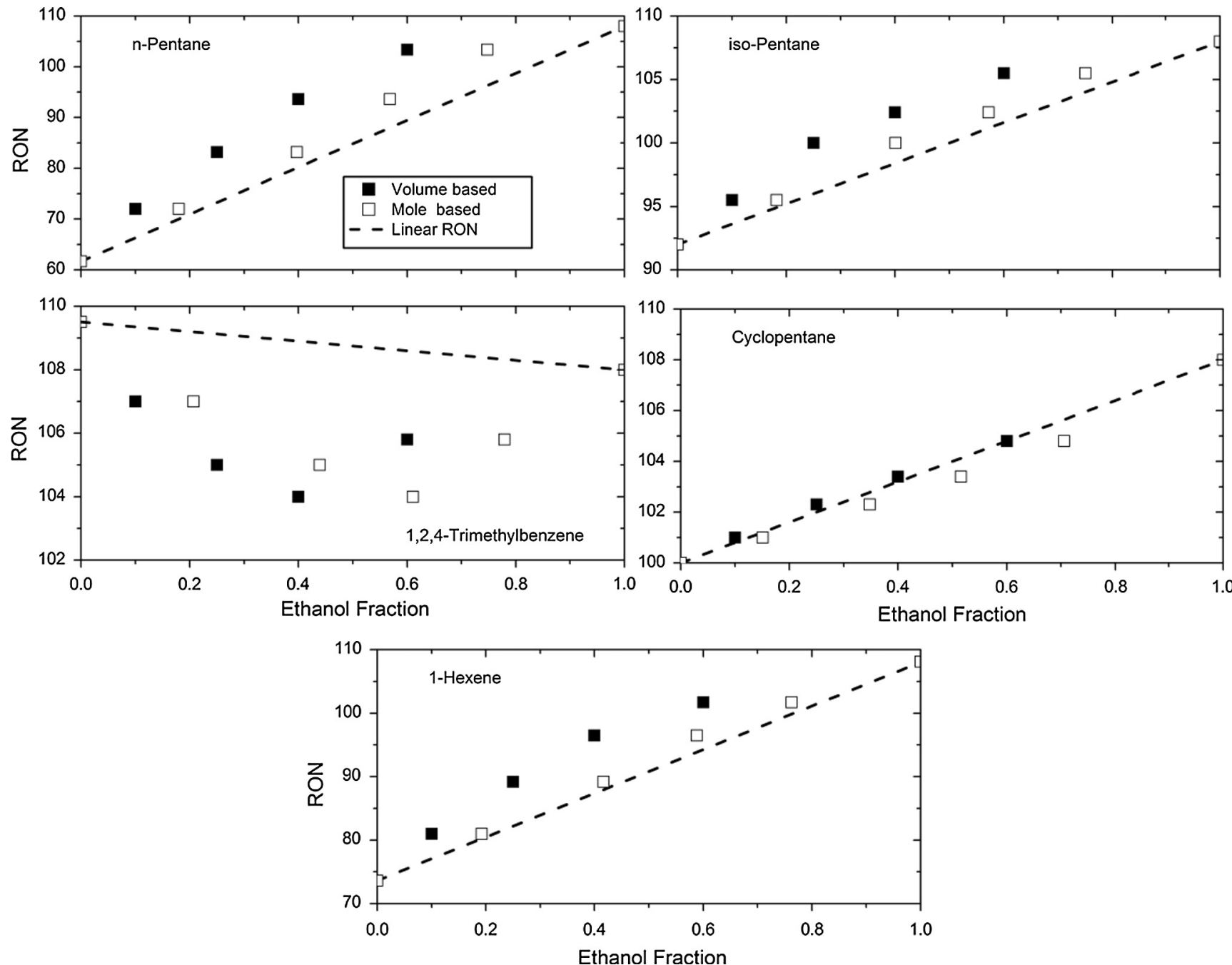

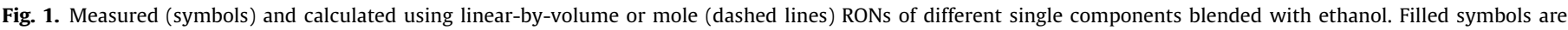
plotted against the volume fraction of ethanol and open symbols are plotted against the mole fraction of ethanol.

that there are distinct synergistic effects (the measured RON is higher than the estimated using linear-by-volume) when blending ethanol with n-pentane, iso-pentane and 1-hexene. 1,2,4-Trimethylbenzene clearly shows an antagonistic effect (the measured RON is lower than the linear-by-volume) when blended with ethanol. Cyclopentane nearly follows the linear-by-volume RON response with the addition of ethanol. Similar synergetic effects are seen with MON when adding ethanol to n-pentane, iso-pentane and 1-hexene, as shown in Fig. 2. The MON values for blends of 1,2,4-trimethylbenzene with ethanol also show antagonistic effect, as expected. Unlike the linear-by-volume relationship of RON for cyclopentane and ethanol mixtures, antagonis- tic effects are observed for MON, as shown in Fig. 2. The synergetic and antagonistic responses mostly decrease when plotting the RON and MON experimental data against the mole fraction of ethanol. This is expected because the data points are shifted towards the linear-by-mole line when analyzed on molar basis. In some cases, the slightly synergistic behavior changes to antagonism when plotting the data against the mole fraction of ethanol as can be seen from the cyclopentane/ethanol RON measurements. However, there are still synergistic and antagonistic RON and MON responses when adding ethanol to the five studied molecules. These synergistic and antagonistic effects are quantified and discussed in details in the subsequent sections. 

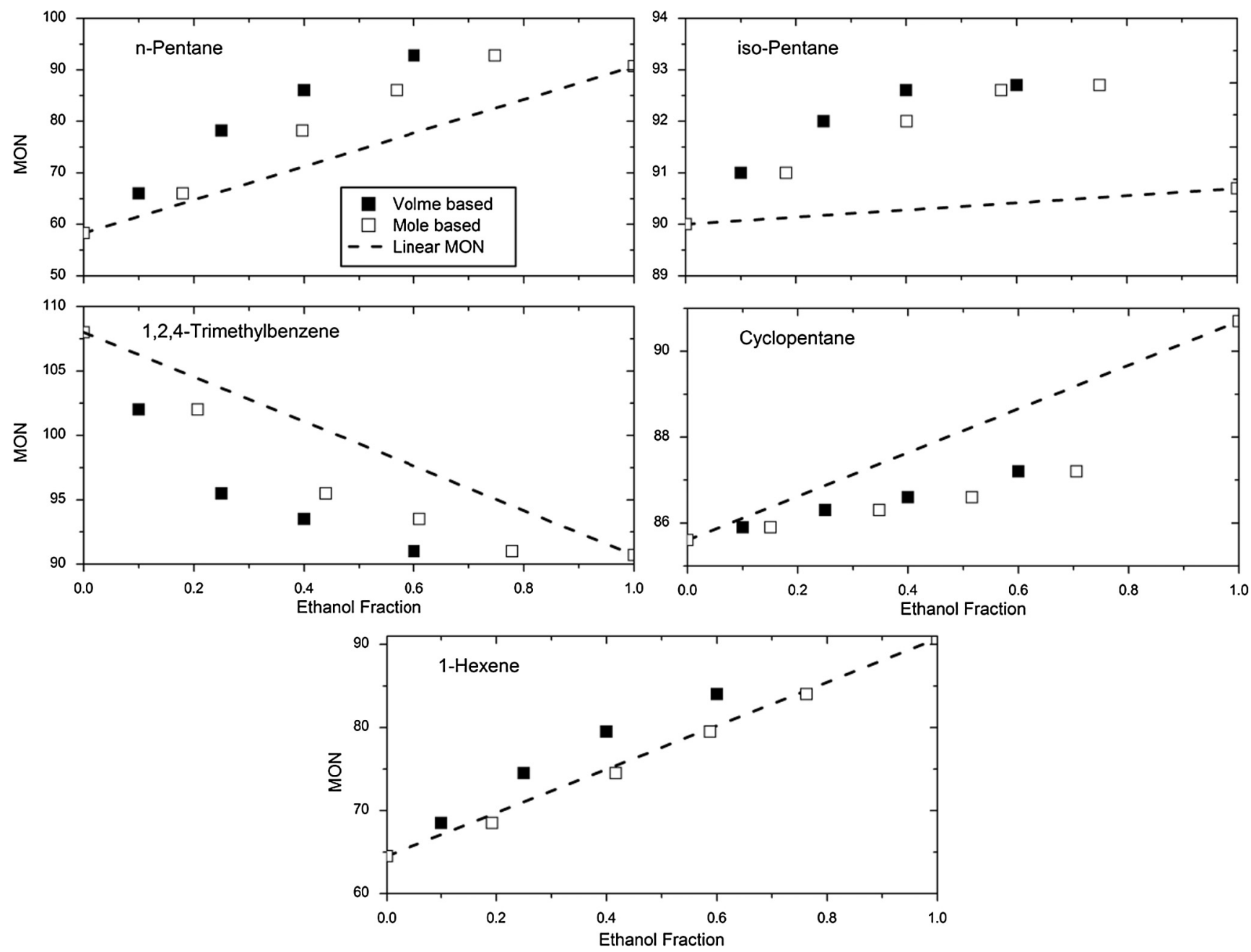

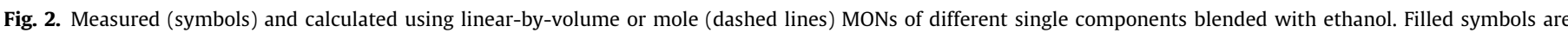
plotted against the volume fraction of ethanol and open symbols are plotted against the mole fraction of ethanol.

The RON and MON for the blends of FACE gasolines with ethanol measured in this work are presented in Table 3. The measured RON and MON data along with the linear-by-volume or mole calculations are also presented against the ethanol volume and mole fractions in Fig. 3 and Fig. 4, respectively. Previous RON and MON measurements of FACE gasolines/ethanol blends are reported in literature [51]. However, these measurements are only available for FACE A, B, C and $\mathrm{H}$ and with ethanol addition up to $30 \mathrm{vol} \%$. The new measurements reported here serve as an extension of the CRC work and the overlapping measurements are compared in the subsequent plots. The measured RON and MON (Table 3) of the base FACE gasolines are within the reproducibility limits of the values reported in [51] and Table 1. Similarly, excellent agreements are observed between the RON and MON measurements reported here and the ones from [51] for FACE gasolines/ethanol blends. Regarding the octane response when blending FACE gasolines with ethanol, it is clear that the RON and MON of all tested FACE gasoline fuels exhibit synergistic effects. The scale of this synergy depends on the composition of the base FACE gasoline. For example, the synergistic effect of FACE F with ethanol is higher than that of FACE G despite having similar base RON and MON, as shown in Fig. 3 and Fig. 4, respectively. For example, $D_{\text {RON }}$ ( RON $\left._{\text {Measured }}-\mathrm{RON}_{\text {Linear-by-volume }}\right)$ of FACE F with 10,25 and $40 \mathrm{vol}$ $\%$ of ethanol are 3.3, 5.6 and 5, respectively. However, $D_{\text {RON }}$ of FACE $G$ with 10,25 and 40 vol\% of ethanol are $1.2,3.1$ and 2, respectively. This is due to the higher aromatics content in FACE G compared to FACE F. Similar to the previous analysis on the RON and MON of pure components/ethanol mixtures, the mole based ON responses are lower than the volume based ones. These distinct effects are also discussed in more details in the subsequent sections.

Table 3

Measured RONs and MONs of FACE gasolines blended with ethanol.

\begin{tabular}{|c|c|c|c|c|c|c|c|c|c|c|c|c|}
\hline \multirow[b]{2}{*}{ Ethanol vol\% } & \multicolumn{2}{|c|}{ FACE A } & \multicolumn{2}{|c|}{ FACE C } & \multicolumn{2}{|c|}{ FACE F } & \multicolumn{2}{|c|}{ FACE G } & \multicolumn{2}{|c|}{ FACE I } & \multicolumn{2}{|c|}{ FACE J } \\
\hline & RON & MON & RON & MON & RON & MON & RON & MON & RON & MON & RON & MON \\
\hline 0 & 83.6 & 82.9 & 84.4 & 83.0 & 94.2 & 87.4 & 96.4 & 84.9 & 69.5 & 69.0 & 71.8 & 66.9 \\
\hline 10 & 92.0 & 88.0 & 92.2 & 87.1 & 98.9 & 88.5 & 98.8 & 86.1 & 79.9 & 78.0 & 79.0 & 73.6 \\
\hline 25 & 100.7 & 90.6 & 100.3 & 90.5 & 103.2 & 89.5 & 102.4 & 87.9 & 92.6 & 85.3 & 89.8 & 81.7 \\
\hline 40 & 104.1 & 91.7 & 104.1 & 91.0 & 104.7 & 90.3 & 103.0 & 88.5 & 100.4 & 88.3 & 98.0 & 85.9 \\
\hline 60 & 106.0 & 91.3 & 105.8 & 91.3 & 105.7 & 90.5 & 105.0 & 88.9 & 104.1 & 89.7 & 103.6 & 88.2 \\
\hline
\end{tabular}



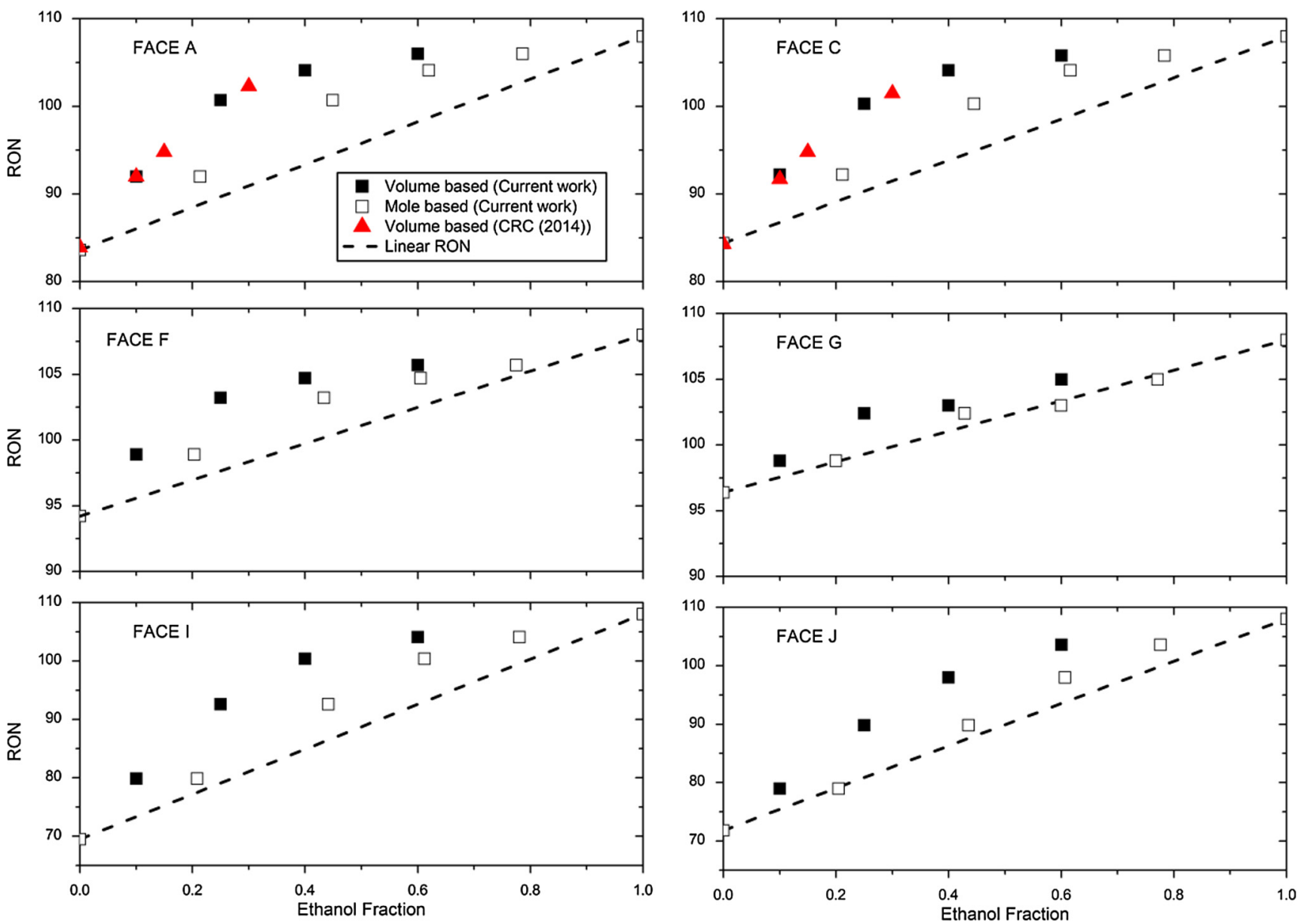

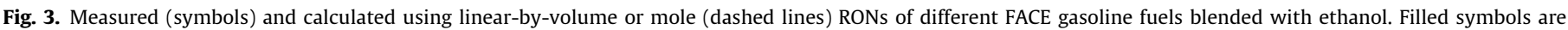
plotted against the volume fraction of ethanol and open symbols are plotted against the mole fraction of ethanol.

\section{Methodology to develop a blending rule of ethanol with PRFs and TPRFs}

The development of the blending rule starts with PRF and TPRF mixtures with ethanol, since these are widely used surrogates for gasoline fuels [44,71-76]. Also, establishing an octane number regression model for PRFs/ethanol and TPRFs/ethanol blends would significantly aid the efforts in designing modern engines fuels with optimum ON response due to the addition of ethanol. This is achieved because detailed [38] and reduced [77] chemical kinetic models are available in literature for PRF and TPRF mixtures with ethanol, thereby enabling different types of engine simulations ranging from $0 \mathrm{D}$ to 3D. Note, that we recently [44] developed a molar based blending rule for predicting the ON of PRF and TPRF mixture with ethanol; however, the complexity of that model hinders it extension to development of blending rules for other multicomponent surrogates with ethanol. The complexity of the molar based model is introduced by the definition of the linear and non-linear sections of the octane response. The transition from linear to the non-linear sections was defined as a function of the PRF number of the simple PRF and TPRF surrogates. The determination of the transition point of multi-component mixtures is not a direct function of the PRF number anymore but rather a complicated parameter because of the unknown interactions between the various species. Therefore, a simpler volume based model with fewer parameters is proposed herein. The following steps were followed to develop the proposed model.

\subsection{Scaling parameter $(D)$ of n-heptane, iso-octane and toluene}

As previously noted, there are distinct synergistic and antagonistic effects when blending ethanol with different pure components. Therefore, a variable termed D was defined first. D, similar to the scaling parameter suggested by Anderson et al. [48], is the difference between the measured ON (RON and MON) and the calculated ones using the linear-by-volume or mole method for mixtures of pure n-heptane, iso-octane and toluene with ethanol as described in Eq. (1).

$D_{\text {ON }, i}=O N_{\text {Measured }, i}-O N_{\text {Linear-by-volume or mole }, i}$

where i refers to the species of interest being n-heptane, iso-octane or toluene and $O N_{\text {Linear-by-volume or mole }, i}$ is defined as,

$O N_{\text {Linear-by-volume or mole }, i}=\varnothing_{\text {eth }} \times O N_{\text {eth }}+\left(1-\varnothing_{\text {eth }}\right) \times O N_{i}$

where $\varnothing_{\text {eth }}$ is the ethanol volume or mole fraction and $O N_{e t h}$ and $O N_{i}$ are the RON or MON of ethanol and pure component i, respectively. Fig. 5 below shows the volume and mole based $D_{\text {RON }}$ and $D_{\text {MON }}$ for blends of pure n-heptane, iso-octane and toluene with ethanol. The data used to calculate the $\mathrm{D}_{\mathrm{ON}}$ (Fig. 5) are taken from [49] and are listed in Table 4. D is a direct measure of the synergistic and antagonistic effects of the fuel blend with ethanol. In other words, there is a synergistic effect between the fuel and ethanol if D is positive and an antagonistic effect when $D$ is negative. The degree of this synergistic or antagonistic effect is measured by the values 

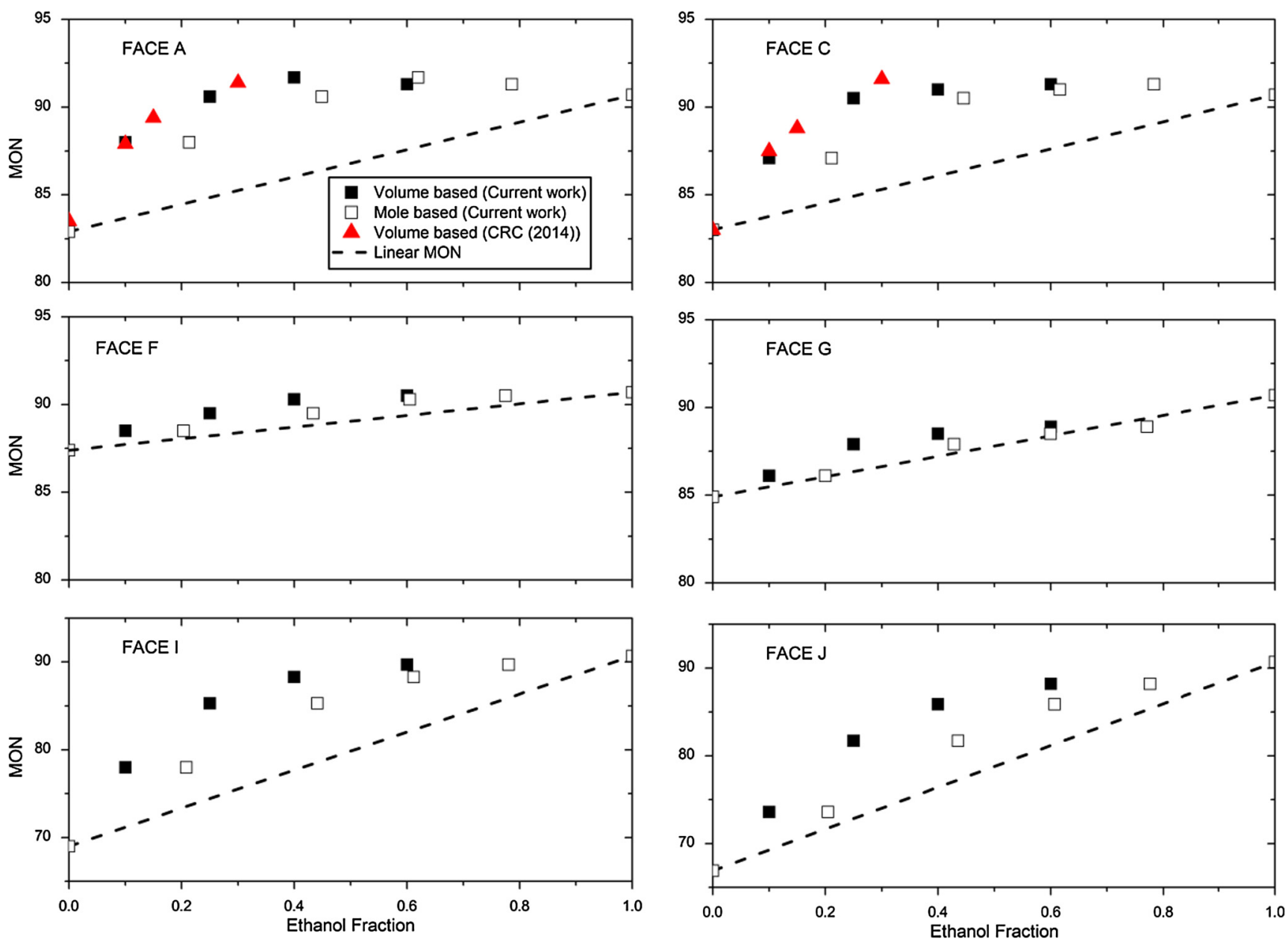

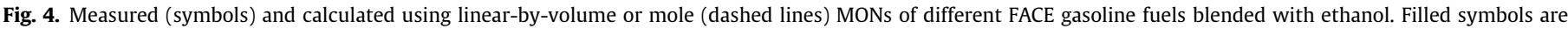
plotted against the volume fraction of ethanol and open symbols are plotted against the mole fraction of ethanol.

of D. Regarding the volume based RON of ethanol mixtures with n-heptane, iso-octane and toluene, n-heptane and iso-octane have synergistic while toluene has antagonistic effects as can be seen from Fig. 5a. The volume based MON of n-heptane and toluene mixtures with ethanol show similar trends as RON, however, MON of iso-octane blends with ethanol are very close to the linearby-volume calculations as can be seen from the near zero values

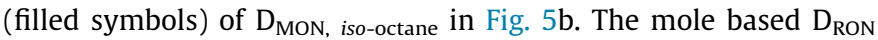
and $\mathrm{D}_{\mathrm{MON}}$ of iso-octane and toluene blends with ethanol are very similar to those the volume based ones with the peak shifting to higher ethanol mole fraction. However, the mole based $D_{\text {RON }}$ and $D_{\text {MON }}$ of $n$-heptane/ethanol mixtures are significantly lower than the volume based ones and the peaks are also shifted to higher ethanol mole fractions.

It has been previously shown $[27,44,45,48,49]$ that a linear-bymole blending may better reproduce octane number response with ethanol addition. Also, it was earlier demonstrated that the degree of synergism and antagonism may change if data is analyzed on molar basis. However, D value trends indicate that both volume and mole based analyses clearly show synergetic and antagonistic responses, albeit the magnitude varies with the method used. D values based on volume blending tend to be larger than those for molar blending for cases when there are large differences between base fuels RON (e.g., n-heptane/ethanol mixtures). Nevertheless, the linear-by-volume is used here as the basis of $\mathrm{D}$ definition because qualitative trends are adequately captured and for simpler applicability, especially in industry. The model presented herein is considered one of the potential simple approaches to analyze the data.

The volume based D values shown in Fig. 5 were fitted using high order polynomial expressions in Microsoft Excel to obtain the highest $R^{2}$ values as can be seen from the equation below.

$D_{\mathrm{ON}, i}=a \times \varnothing_{\text {eth }}^{5}+b \times \varnothing_{\text {eth }}^{4}+c \times \varnothing_{\text {eth }}^{3}+d \times \varnothing_{\text {eth }}^{2}+e \times \varnothing_{\text {eth }}+f$

where $\mathrm{a}, \mathrm{b}, \mathrm{c}, \mathrm{d}$, e and $\mathrm{f}$ are the polynomial fitting constants. These polynomial constants of $D_{R O N}$ and $D_{\text {MON }}$ along with the $R^{2}$ values are provided in Table 5 . Note that the values for constant $f$ are not zeros and can be noticeable in some cases such as $D_{\text {MON }}$ for n-heptane $(-1.38)$. The values of the constants including $\mathrm{f}$ were obtained from the simple polynomial fittings while maximizing the $\mathrm{R}^{2}$ values and having a non-zero value for $f$ does not reflect a modification to the assumed octane rating of the pure component.

A preliminary model for predicting RON and MON of any PRF or TPRF blends with ethanol is proposed.

$O N_{T P R F+e t h}=O N_{\text {Linear-by-volume }}+\sum_{i=1}^{N}\left(D_{O N, M i x, i}\right)$

where i refers to the pure components, $\mathrm{N}$ is the number of components present in the base TPRF mixture and $D_{\mathrm{ON}, \mathrm{Mix}, i}$ is the individual $\mathrm{D}$ effect for species $\mathrm{i}$ when mixed with ethanol but normalized by the volume fraction of species $i$ in the base TPRF mixture. This term is defined as, 


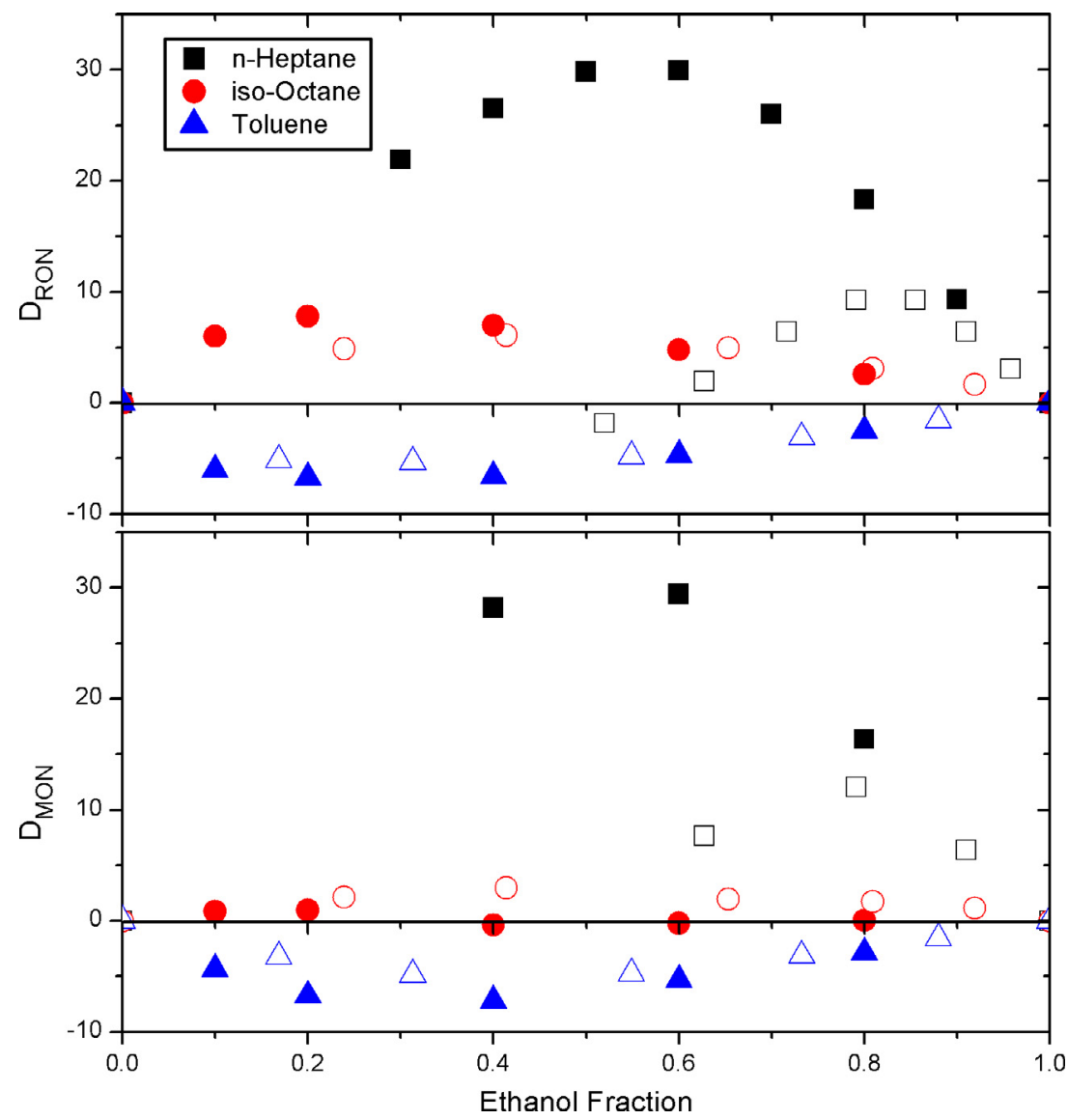

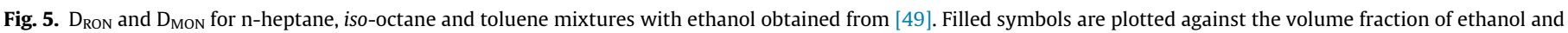
open symbols are plotted against the mole fraction of ethanol.

Table 4

Measured RONs and MONs of n-heptane, iso-octane and toluene blended with ethanol. The data are taken from [49].

\begin{tabular}{|c|c|c|c|c|c|c|}
\hline \multirow[b]{2}{*}{ Ethanol vol\% } & \multicolumn{2}{|c|}{ n-Heptane } & \multicolumn{2}{|c|}{ iso-Octane } & \multicolumn{2}{|c|}{ Toluene } \\
\hline & RON & MON & RON & MON & RON & MON \\
\hline 0 & 0.00 & 0.00 & 100.0 & 100.0 & 120.0 & 107.0 \\
\hline 10 & - & - & 106.8 & 99.9 & 112.8 & 101.0 \\
\hline 20 & - & - & 109.4 & 99.1 & 110.9 & 97.0 \\
\hline 30 & 54.3 & - & - & - & - & - \\
\hline 40 & 69.7 & 64.5 & 110.2 & 95.9 & 108.6 & 93.3 \\
\hline 50 & 83.8 & - & - & - & - & - \\
\hline 60 & 94.7 & 83.8 & 109.2 & 94.2 & 108.1 & 91.9 \\
\hline 70 & 101.6 & - & - & - & - & - \\
\hline 80 & 104.7 & 88.9 & 109.0 & 92.6 & 107.9 & 91.1 \\
\hline 90 & 106.5 & - & - & - & - & - \\
\hline 100 & 108.5 & 90.7 & 108.5 & 90.7 & 108.5 & 90.7 \\
\hline
\end{tabular}

Table 5

Polynomial fitting constants of $\mathrm{D}_{\mathrm{RON}}$ and $\mathrm{D}_{\mathrm{MON}}$ for mixture of ethanol with pure n-heptane, iso-octane and toluene.

\begin{tabular}{|c|c|c|c|c|c|c|}
\hline \multirow[b]{2}{*}{ Polynomial constants } & \multicolumn{2}{|c|}{ n-Heptane } & \multicolumn{2}{|c|}{ iso-Octane } & \multicolumn{2}{|l|}{ Toluene } \\
\hline & $\mathrm{D}_{\mathrm{RON}}$ & $\mathrm{D}_{\text {MON }}$ & $\mathrm{D}_{\mathrm{RON}}$ & $\mathrm{D}_{\mathrm{MON}}$ & $\mathrm{D}_{\mathrm{RON}}$ & $\mathrm{D}_{\mathrm{MON}}$ \\
\hline $\mathrm{a}$ & 0.00 & 0.00 & -108.34 & 0.00 & -257.40 & -608.60 \\
\hline $\mathrm{b}$ & 153.21 & 0.00 & 209.37 & -15.57 & 549.58 & 1482.80 \\
\hline c & -343.79 & 39.09 & -39.70 & 40.89 & -316.37 & -1213.90 \\
\hline $\mathrm{d}$ & 130.30 & -187.89 & -127.48 & -34.68 & 35.71 & 408.30 \\
\hline $\mathrm{e}$ & 59.96 & 148.42 & 66.24 & 9.28 & -11.18 & -68.30 \\
\hline $\mathrm{f}$ & 0.20 & -1.38 & 0.00 & 0.21 & -0.33 & 0.70 \\
\hline $\mathrm{R}^{2}$ values & 0.999 & 0.994 & 0.999 & 0.903 & 0.991 & 0.999 \\
\hline
\end{tabular}


$D_{\text {ON.Mix }, i}=\varnothing_{\text {i,base }} \times D_{\text {ON }, i}$

and $\varnothing_{i \text {,ase }}$ is the volume fraction of species $i$ in the base TPRF mixture. For example, when $20 \mathrm{vol} \%$ of ethanol is added to a base TPRF mixture that contains $50 \mathrm{vol} \% \mathrm{n}$-heptane, $30 \mathrm{vol} \%$ iso-octane and 20 vol\% toluene, $\mathrm{N}$ would be equal to 3 , i is n-heptane, iso-octane and toluene, $\varnothing_{\text {i.base }}=0.5,0.3$ ad 0.2 for n-heptane, iso-octane and toluene, respectively and $D_{O N, i}$ is calculated using Eq. (3). $O N_{\text {Linear-by-volume }}$ is calculated as,

$O N_{\text {Linear-by-volume }}=\varnothing_{\text {eth }} \times O N_{\text {eth }}+\left(1-\varnothing_{\text {eth }}\right) \times O N_{T P R F, \text { base }}$

where $O N_{\text {TPRF, base }}$ are the RON and MON of the base TPRF mixture without ethanol addition.

\subsection{Interactions between molecules}

There are cross-reactions between the different components in TPRF mixtures when blended with ethanol $[38,45]$. These interactions between the molecules cannot be neglected when developing a blending rule for TPRF+ethanol mixtures and hence need to be accounted for as per the expression below.

$$
\begin{aligned}
& O N_{T P R F+e t h}=O N_{\text {Linear-by-volume }}+\sum_{i=1}^{N}\left(D_{O N, M i x, i}\right) \\
& +\alpha_{H, I} \sqrt{\left(D_{O N, M i x, H} \times D_{O N, M i x, I}\right)} \\
& +\alpha_{H, T} \sqrt{\left(D_{\text {ON,Mix }, H} \times D_{\text {ON,Mix }, T}\right)} \\
& +\alpha_{I, T} \sqrt{\left(D_{\text {ON,Mix,I }} \times D_{O N, M i x, T}\right)}
\end{aligned}
$$

where $D_{O N, M i x, H}, D_{O N, M i x, I}$ and $D_{O N, M i x, T}$ are calculated using Eq. (5) for $\mathrm{n}$-heptane, iso-octane and toluene, respectively. $\alpha_{H . I}$ is the introduced scaling factor for the interactions between $n$-heptane and

\section{Table 6}

Interaction factors between n-heptane, iso-octane and toluene when blended with ethanol.

\begin{tabular}{lll}
\hline Interaction factors & RON & MON \\
\hline$\alpha_{H, I}$ & 0.52 & 1.60 \\
$\alpha_{H, T}$ & 0.55 & 0.30 \\
$\alpha_{I, T}$ & -0.70 & -1.55 \\
\hline
\end{tabular}

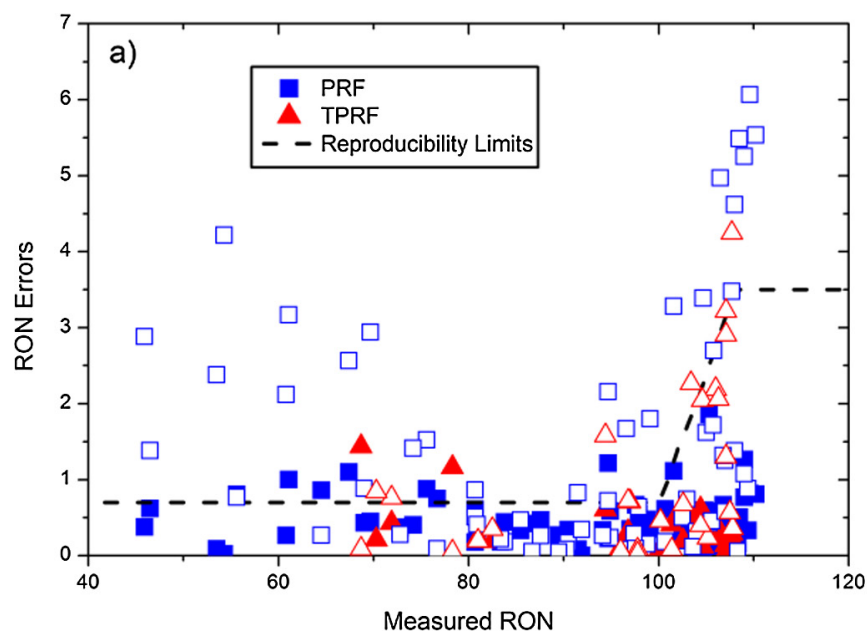

iso-octane when blended with ethanol. Similarly, $\alpha_{H T}$ is for the interactions between n-heptane and toluene and $\alpha_{I, T}$ accounts for the cross-reactions between iso-octane and toluene when blended with ethanol. The interactions between hydrocarbons on ethanol blending are represented by the products of terms from single components to comply with the boundary conditions. In the current form, Eq. (7) can be utilized to predict the ON of pure components/ethanol blends. For example, the RON and MON of nheptane/ethanol mixture can be calculated using Eq. (7) because the interaction terms are eliminated due to the products nature. The introduced scaling factors are optimized based on the predictions of ON of the various PRF and TPRF blends with ethanol available from literature $[44,49]$. A manual method to optimize the scaling factors was utilized here. The summation of the octane number errors $\left(\mathrm{ON}_{\text {Measured }}-\mathrm{ON}_{\text {Predicted }}\right)$ was calculated for a range of scaling factors until a local minimum is obtained. The range was then narrowed down around that local minimum until a new minimum is found. First, the $\alpha_{H, I}$ was optimized using the RON and MON data of the various PRF/ethanol mixtures. The optimized $\alpha_{H . I}$ values from the previous step were kept unchanged when optimizing $\alpha_{H, T}$ and $\alpha_{I T}$ using the same manual approach for the various TPRF/ethanol mixtures. The optimized interaction factors are presented in Table 6.

\subsection{Validation of the TPRF+ethanol model}

The PRF/TPRF+ethanol model presented in Eq. (7) was validated against the various PRF and TPRF with ethanol data found in literature $[44,49]$. The RON and MON of all the existing PRF and TPRF blends with ethanol excluding the base PRFs, TPRFs and ethanol were calculated using the developed model. The PRF and TPRF with ethanol data were also predicted using the model proposed by Aronsson et al. [50]. An ON error which is the difference between the measured and predicted ON was defined as a measure of the accuracy of the model. The absolute values of the ON errors are plotted against the measured ON in Fig. 6. The RON and MON reproducibility limits $[42,43]$ are also shown in Fig. 6. The RON predictions using the developed model are very accurate with the majority (91\%) of the RON errors being within the reproducibility limits as can be seen from Fig. 6a. MON predictions (Fig. 6b) are not as accurate as RON because of the lesser amount

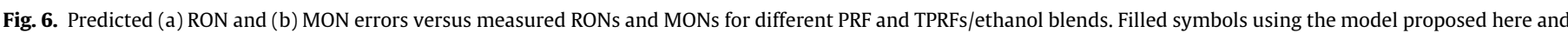

open symbols using Aronsson's blending rule [50].

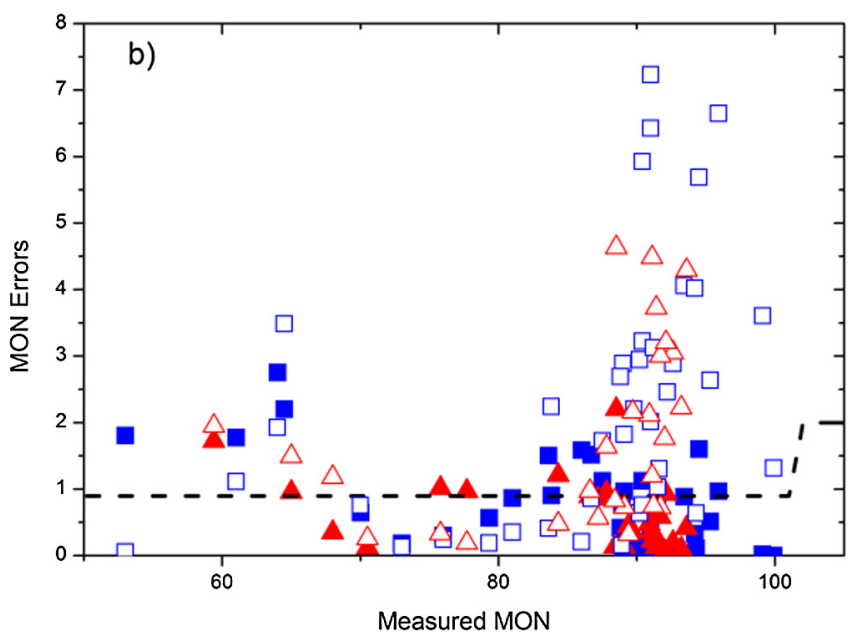


of data used to calibrate the model for MON. However, the MON errors are almost all less than 2 MON and 31\% of the predictions are outside the reproducibility limits. The predictions of the current model are as accurate as the calculations of the previous blending rule [44] despite the fewer number of parameters utilized here. The model proposed here performs better than Aronsson's blending rule where only $70 \%$ of the RON predictions are within the reproducibility limits. MON prediction are even worse with $70 \%$ are outside the reproducibility limits as can be seen from Fig. 6b. The overall ON errors that are outside the reproducibility limits are smaller using the current model compared to Aronssons's where ON errors of 8 are observed. The ON errors predicted by the current model are all less than 3 . The ON errors using Aronssons's model are mainly from the mixtures with high ethanol content. This is expected because they calibrated their model for PRF and TPRF mixtures with ethanol vol\% up to 38\%. The measured, predicted (using the current model) RON and MON and ON errors for the PRF and TPRF/ethanol blends are provided in Supplementary Material. Note that the PRF and TPRF data used here to test the accuracy of the model were the ones used to optimize the scaling factors as detailed in the previous section. The current test is not intended to predict the ON of the mixtures used to develop and optimize the model but rather a sanity check for the relatively simple model (linear-by-volume with few scaling factors) and its optimization process. It is worth noting that more accurate predictions can be obtained by adding more variables in the model and using a more advanced optimization method. However, the level of accuracy presented in Fig. 6 is considered to be acceptable considering the simplicity of the model and the small number of variables.

\section{Model development for multi-component surrogates with ethanol}

Similar to the TPRF model, D for the five additional pure components (n-pentane, iso-pentane, 1,2,4-trimethylbenzene, cyclopentane and 1-hexene) with ethanol were calculated. The volume and mole based $D_{\text {RON }}$ and $D_{\text {MON }}$ values for the above-mentioned species blended with ethanol are presented in Fig. 7. As shown previously, the volume based RON and MON responses due to the addition of ethanol to n-pentane, iso-pentane and 1-hexene exhibit synergistic trends. Regarding 1,2,4-trimethylbenzene mixtures with ethanol, antagonistic effects are observed for both the RON and MON. The volume based octane response due to the addition of ethanol to cyclopentane closely follows the linear-by-volume line as can be seen from the near zero D values. Interestingly, iso-octane and cyclopentane have very different $\mathrm{D}_{\text {RON }}$ values when blended with ethanol despite having very similar base RON values of 100. D values of around 10 are observed for iso-octane/ethanol blends (Fig. 5) while cyclopentane/ethanol mixtures have new zero $D_{\text {Rons. }}$ This indicates that variation in $\mathrm{D}$ values cannot only be attributed to differences in RON of the base fuels, as was shown earlier for n-heptane/ethanol mixtures. As expected, the mole based $D_{\text {RON }}$ and $D_{\text {MON }}$ are lower than the volume based ones as can be seen from the open symbols in Fig. 7. Similar to n-heptane, iso-octane and toluene, the volume based D values were also fitted using polynomial expressions similar to Eq. (3) and the polynomial constants listed in Table 7 along with the $\mathrm{R}^{2}$ values.

Based on these additional D values, a new model for any mixture containing some or all of the 8 studied components (n-heptane, n-pentane, iso-octane, iso-pentane, toluene,

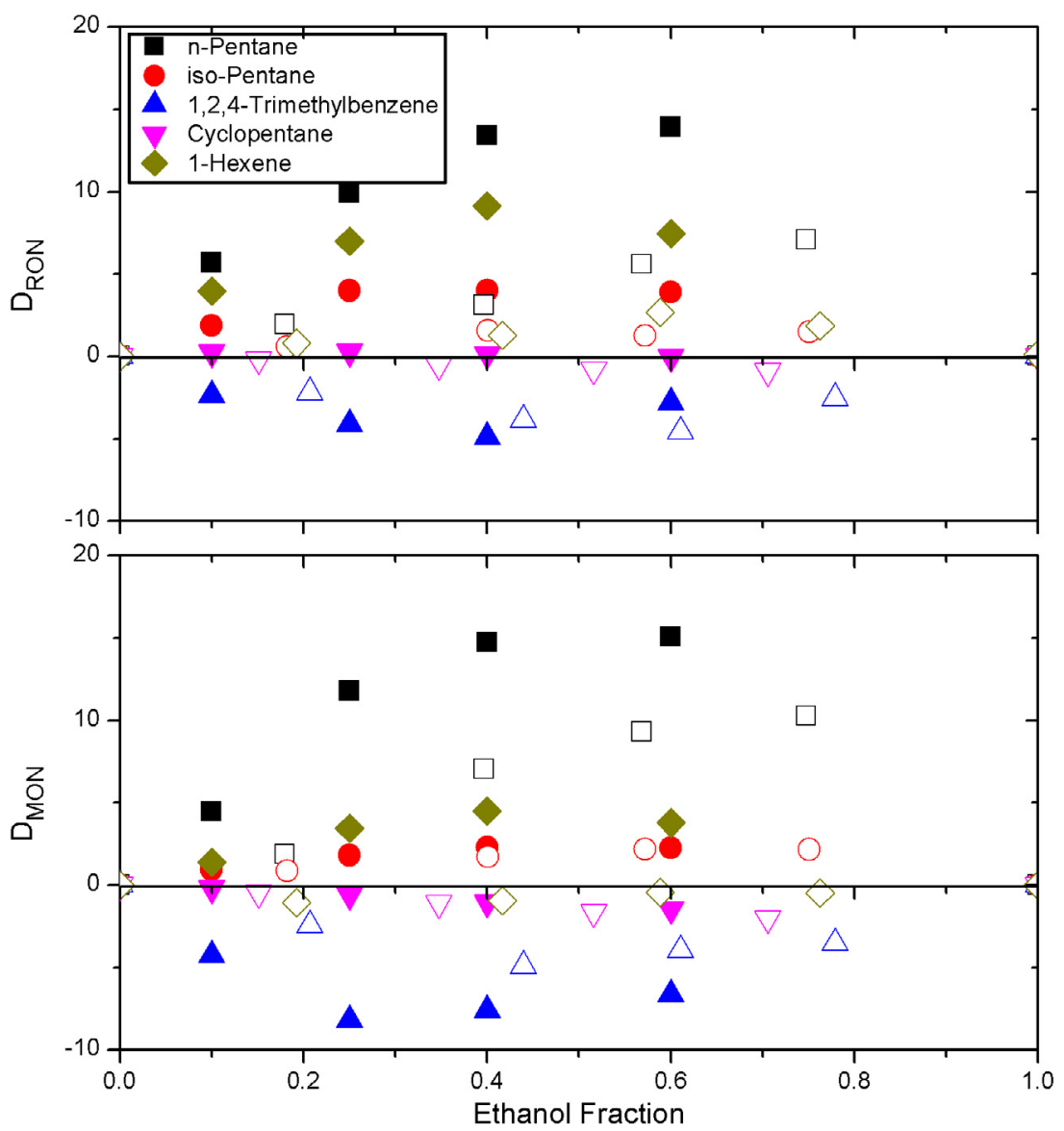

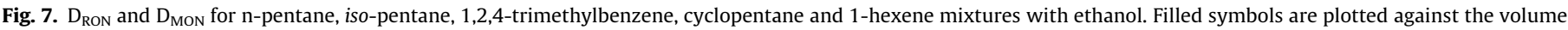
fraction of ethanol and open symbols are plotted against the mole fraction of ethanol. 
Table 7

Polynomial fitting constants of $\mathrm{D}_{\mathrm{RON}}$ and $\mathrm{D}_{\mathrm{MON}}$ for mixture of ethanol with pure n-pentane, iso-pentane, 1,2,4-trimethylbenzene, cyclopentane and 1-hexene.

\begin{tabular}{|c|c|c|c|c|c|c|c|c|c|c|}
\hline \multirow[b]{2}{*}{ Polynomial constants } & \multicolumn{2}{|c|}{ n-Pentane } & \multicolumn{2}{|c|}{ iso-Pentane } & \multicolumn{2}{|c|}{$\begin{array}{l}\text { 1,2,4- } \\
\text { Trimethylbenzene }\end{array}$} & \multicolumn{2}{|c|}{ Cyclopentane } & \multicolumn{2}{|c|}{ 1-Hexene } \\
\hline & $\mathrm{D}_{\mathrm{RON}}$ & $\mathrm{D}_{\mathrm{MON}}$ & $\mathrm{D}_{\mathrm{RON}}$ & $\mathrm{D}_{\mathrm{MON}}$ & $\mathrm{D}_{\mathrm{RON}}$ & $\mathrm{D}_{\mathrm{MON}}$ & $\mathrm{D}_{\mathrm{RON}}$ & $\mathrm{D}_{\mathrm{MON}}$ & $\mathrm{D}_{\mathrm{RON}}$ & $\mathrm{D}_{\mathrm{MON}}$ \\
\hline $\mathrm{a}$ & 0.00 & 0.00 & 0.00 & 0.00 & 0.00 & 0.00 & 0.00 & 0.00 & 0.00 & 0.00 \\
\hline $\mathrm{b}$ & 0.00 & 0.00 & 0.00 & 0.00 & 0.00 & 0.00 & 0.00 & 0.00 & 30.68 & 54.17 \\
\hline c & 0.00 & 0.00 & 11.95 & 1.03 & -30.29 & -41.82 & 4.70 & 8.23 & -33.24 & -92.77 \\
\hline d & -56.15 & -61.47 & -34.77 & -11.13 & 61.06 & 93.10 & -7.22 & -7.14 & -38.09 & 26.51 \\
\hline e & 56.24 & 61.55 & 22.84 & 10.09 & -30.74 & -51.32 & 2.50 & -1.09 & 40.75 & 12.09 \\
\hline f & 0.00 & 0.00 & 0.00 & 0.00 & 0.00 & 0.00 & 0.01 & 0.00 & 0.00 & 0.00 \\
\hline $\mathrm{R}^{2}$ values & 0.995 & 0.996 & 0.989 & 0.999 & 0.986 & 0.987 & 0.972 & 0.999 & 0.996 & 0.999 \\
\hline
\end{tabular}

1,2,4-trimethylbenzene, cyclopentane and 1-hexene) with ethanol is proposed.

$$
\begin{aligned}
\text { ON }_{\text {Mutli-Comp }+ \text { eth }}= & \text { ON } N_{\text {Linear-by-volume }}+\sum_{i=1}^{N}\left(D_{\text {ON,Mix }, i}\right) \\
& +\alpha_{H, I} \sqrt{\left(D_{\text {ON,Mix }, H} \times D_{\text {ON,Mix }, I}\right)} \\
& +\alpha_{H, T} \sqrt{\left(D_{O N, M i x, H} \times D_{O N, M i x, T}\right)} \\
& +\alpha_{I, T} \sqrt{\left(D_{O N, \text { Mix }, I} \times D_{O N, M i x, T}\right)}
\end{aligned}
$$

The proposed model is very similar to the TPRF/ethanol one, however, Eq. (8) accounts for the additional species present in the base multi-component mixture. Only the normalized $D_{O N, M i x, i}$ for the additional five species were considered in the current work. The interactions between the additional components and TPRF species were neglected here because of the unavailability of experimental data of mixtures of the additional pure components with ethanol to calibrate the missing scaling factors. In addition, n-heptane, isooctane and toluene are usually the major constituents of gasoline fuel surrogates, as shown next, and hence the interactions between them needed to be accounted for in the current model. $\mathrm{N}$ is equal to 8 for a base multi-component mixture that contains the studied species and i spans across the molecules present in the mixture.

\section{Model validation against FACE gasolines}

The RON and MON of the studied FACE gasolines blended with ethanol were predicted using the model developed here (Eq. (8)), and then compared with the measured ones to test the accuracy of the proposed blending rule. However, FACE gasolines are composed of hundreds of species, similar to commercial gasoline fuels. Therefore, surrogate fuels that contain some or all of the 8 studied pure components (n-pentane, n-heptane, iso-pentane, iso-octane, toluene, 1,2,4-trimethylbenzene, cyclopentane and 1-hexene) need to be formulated for each of the FACE gasolines. The objective of the current work is not to develop a methodology to formulate surrogates for FACE gasolines or to test the accuracy of the existing approaches, but rather to predict the octane response when adding ethanol to multi-component mixtures and compare them with those of the real FACE gasolines. Consequently, two different surrogates for each FACE gasoline were formulated based on different methodologies to assess the merits of each. The first surrogate (surrogate \#1) is formulated to match RON and MON of the FACE gasoline without any constraints on the molecular class distribution (paraffins, iso-paraffins, olefins, naphthenes and aromatics (PIONA)) while having the 8 available species. The second surrogate (surrogate \#2) is developed so it has RON, MON and PIONA compositions close to those of the FACE gasolines. Two additional surrogates termed the TPRF and PIONA surrogates were formulated and tested. The TPRF surrogate is the simplest and contains only nheptane, iso-octane and toluene (TPRF) to match the RON and MON of the base FACE gasolines and the PIONA surrogate is formulated to match the hydrocarbon distribution of the base FACE gasolines. These were considered complimentary and their details along with the predictions are provided in Supplementary Material. The logic behind formulating multiple surrogates for each FACE gasoline is to examine the effect of the composition of the surrogates on the octane response due to the addition of ethanol. By definition, the calculated ON of surrogates \#2 and the PIONA surrogate (Supplementary Material) don't exactly match those of the base FACE gasolines. Therefore, the ON increase or decrease due to the addition of ethanol to the surrogates are compared with the measured FACE gasolines/ethanol ones and are used to test the accuracy of the developed model instead of the absolute ON errors. $D_{\text {ON }}$ errors defined as $D_{\mathrm{ON}}$, Measured $-\mathrm{D}_{\mathrm{ON}}$, Calculated are presented in the subsequent sections against the measured ON. Evaluating the $\mathrm{D}_{\mathrm{ON}}$ errors instead of the ON errors shifts the focus to the effect of the surrogate composition on the magnitude of the synergistic and antagonistic behavior of gasoline/ethanol blends without being concerned about the deviations between the ON of the base FACE gasolines and their surrogates.

\subsection{Surrogate \#1: RON and MON multi-components surrogates}

This surrogate was formulated to match the RON and MON of the FACE gasolines while taking into consideration all 8 available species. The methodology developed by Ghosh et al. [78] was utilized to formulate surrogates \#1 without any constraints on the compositions of these surrogates. Microsoft Excel solver was used to calculate the compositions of surrogates \#1. The solver was given initial concentrations of the 8 species based on the PIONA of the FACE gasolines. The compositions of the 8 species were allowed to change freely in order to match the calculated RON and MON of the surrogates with those of the base FACE gasolines. The RON and MON of the 8 species used in the surrogate formulations were taken from the current measurements and from $[42,43]$ and are shown in Table 8. The compositional details as well as the calculated RON and MON of surrogates \#1 are shown in Table 9. It can be observed from Table 9 that the compositions of surrogates \#1 can be very different than the equivalent FACE gasolines. For example, FACE I \#1 has 29.6 vol\% n-paraffins and 59.1 vol\% iso-

Table 8

RON and MON of the 8 components studied in this work.

\begin{tabular}{llll}
\hline Component & RON & MON & Reference \\
\hline n-Pentane & 61.7 & 58.3 & Current work \\
n-Heptane & 0 & 0 & {$[42,43]$} \\
iso-Pentane & 92 & 90 & Current work \\
iso-Octane & 100 & 100 & {$[42,43]$} \\
Toluene & 118 & 107 & {$[42,43]$} \\
1,2,4-Trimethylbenzene & 109.5 & 108 & Current work \\
Cyclopentane & 100 & 85.6 & Current work \\
1-Hexene & 73.6 & 64.5 & Current work \\
\hline
\end{tabular}


Table 9

FACE gasoline surrogates \#1 compositional details.

\begin{tabular}{|c|c|c|c|c|c|c|c|c|c|c|}
\hline & n-P vol\% & n-H vol\% & i-P vol\% & $\mathrm{i}-\mathrm{O}$ vol\% & Tol vol\% & 1,2,4-TMB vol\% & C-p vol\% & 1-H vol\% & $\mathrm{RON}^{*}$ & $\mathrm{MON}^{*}$ \\
\hline FACE A\#1 & 10.923 & 8.650 & 42.794 & 33.362 & 0.429 & 0.342 & 2.738 & 0.763 & 83.6 & 83.0 \\
\hline FACE C\#1 & 23.871 & 6.080 & 9.293 & 55.788 & 0.099 & 3.570 & 0.364 & 0.937 & 84.4 & 83.0 \\
\hline FACE F\#1 & 2.386 & 3.136 & 17.287 & 62.191 & 0.054 & 4.243 & 8.793 & 1.910 & 94.2 & 87.4 \\
\hline FACE G\#1 & 5.750 & 2.780 & 16.605 & 34.095 & 2.028 & 24.087 & 11.934 & 2.722 & 96.4 & 84.9 \\
\hline FACE I\#1 & 0.993 & 28.586 & 19.040 & 40.078 & 1.217 & 0.059 & 3.714 & 6.314 & 69.5 & 69.0 \\
\hline FACE J\#1 & 3.899 & 40.090 & 21.438 & 0.000 & 32.029 & 0.000 & 1.806 & 0.738 & 71.8 & 66.9 \\
\hline
\end{tabular}

The RON and MON are calculated using the method of Ghosh et al. [78].

paraffins compared to $14.4 \mathrm{vol} \%$ and $74.7 \mathrm{vol} \%$ present in the real FACE I gasoline fuel (Table 1). These discrepancies in matching the PIONA distribution of the FACE gasolines might be due to the inaccuracy of the utilized surrogate formulation blending rule or the lack of additional species available to formulate these surrogates.

The RON and MON of FACE surrogates \#1 mixtures with ethanol, excluding the base surrogates and pure ethanol, were predicted using Eq. (8) and the $\mathrm{D}_{\mathrm{ON}}$ prediction errors are plotted against the measured values and are presented in Fig. 8. The RON predictions of FACE surrogates \#1 are acceptable with $37 \%$ of the predictions are outside the reproducibility limits. MON predictions are however less accurate than RON with $50 \%$ of the prediction are outside the reproducibility limits. The measured $D_{O N}$ for FACE gasolines and the calculated $\mathrm{D}_{\mathrm{ON}}$ for surrogates \#1 are provided in Supplementary Material.

\subsection{Surrogate \#2: RON, MON and PIONA surrogates}

This surrogate was developed so it has RON, MON and PIONA composition values close to the equivalent FACE gasolines. Ghosh et al. [78] blending rule was used to match the RON and MON of the FACE gasolines, however, the PIONA of the surrogate was

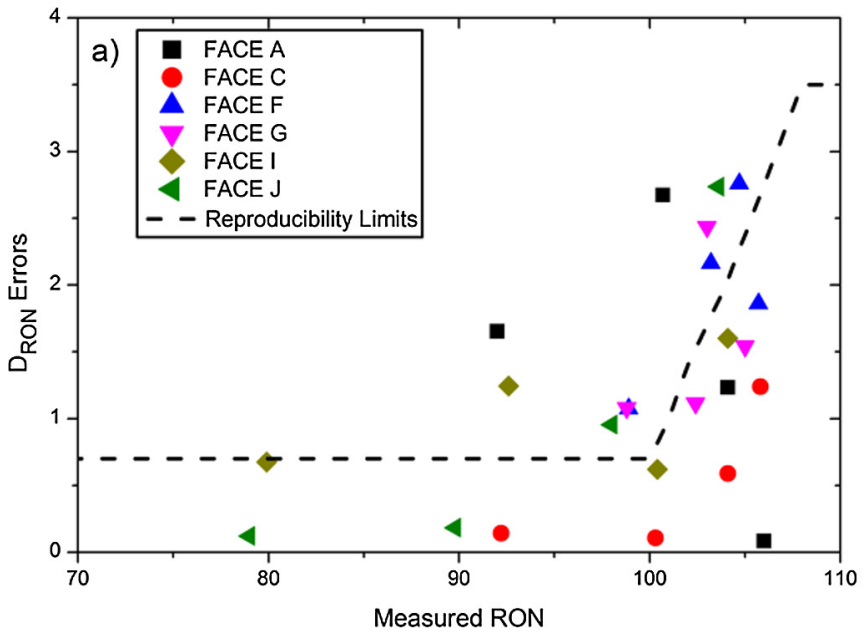

allowed to change within $20 \%$ of the actual FACE fuel hydrocarbon class composition. The compositional details as well as the $\mathrm{ON}$ of FACE surrogates \#4 are listed in Table 10. These surrogates were considered as compromises between surrogates \#1 and the PIONA surrogates (Supplementary Material). Similar to FACE PIONA surrogates, the RON and MON of surrogates \#2 are different than their equivalent FACE gasolines because of the constraints on the PIONA. However, the ON of the base surrogates \#2 are closer to their respective FACE gasolines than PIONA surrogates because of the $20 \%$ limit on the PIONA. Note that the sensitivity (RON-MON) of FACE A surrogate \#2 is negative as per the calculations using Ghosh's method [78]. This highlights some inaccuracy in Ghosh's method because none of the considered components have negative sensitivities.

RON and MON of FACE surrogates \#2 blends with ethanol were calculated using the developed model and the $\mathrm{D}_{\mathrm{ON}}$ errors are presented in Fig. 9. Similar to PIONA surrogates, the $D_{\text {RON }}$ predictions are accurate where $71 \%$ of the predictions are within the reproducibility limits. Surrogates $\# 2 /$ ethanol $\mathrm{D}_{\text {MON }}$ prediction are less accurate ( $55 \%$ of $D_{\text {MON }}$ errors are outside the reproducibility limits) than surrogates \#1 as can be seen from Fig. 9b. The measured $D_{O N}$ for FACE gasolines and the calculated $D_{\mathrm{ON}}$ for surrogates \#2 are provided in Supplementary Material.

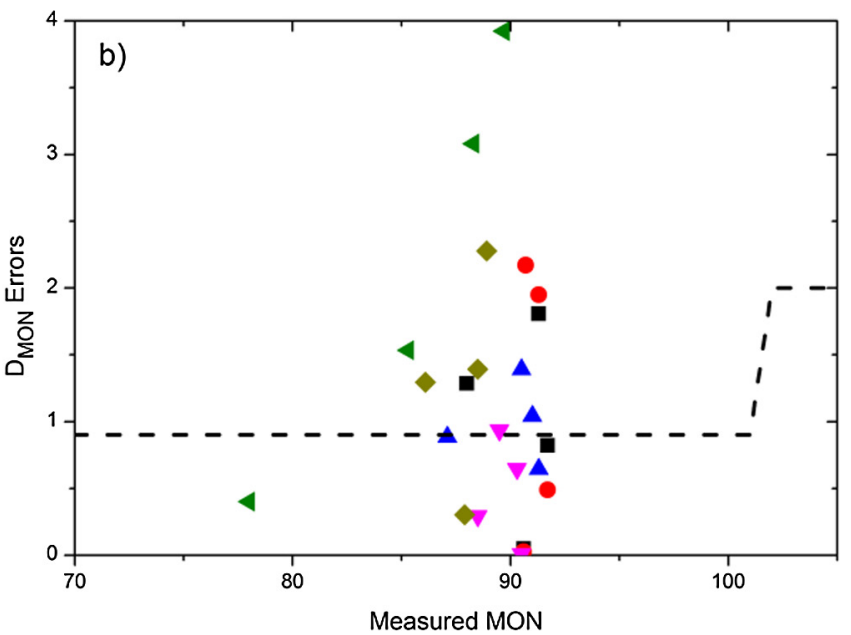

Measured MON

Fig. 8. Predicted (a) $D_{R O N}$ and (b) $D_{M O N}$ errors versus measured RONs and MONs for FACE surrogates \#1/ethanol blends using the developed model.

Table 10

FACE gasoline surrogates \#2 compositional details.

\begin{tabular}{|c|c|c|c|c|c|c|c|c|c|c|}
\hline & n-P vol\% & n-H vol\% & i-P vol\% & i-O vol\% & Tol vol\% & 1,2,4-TMB vol\% & C-p vol\% & 1-H vol\% & $\mathrm{RON}^{*}$ & MON" \\
\hline FACE A\#2 & 6.203 & 7.799 & 20.671 & 63.480 & 0.167 & 0.137 & 1.290 & 0.252 & 88.0 & 89.1 \\
\hline FACE C\#2 & 23.403 & 5.998 & 9.057 & 56.945 & 0.079 & 3.066 & 0.433 & 1.019 & 84.5 & 82.9 \\
\hline FACE F\#2 & 1.759 & 1.759 & 11.665 & 59.254 & 0.074 & 9.183 & 8.777 & 7.530 & 92.7 & 77.1 \\
\hline FACE G\#2 & 3.720 & 1.751 & 10.652 & 27.792 & 1.749 & 38.380 & 9.364 & 6.592 & 96.9 & 78.7 \\
\hline FACE I\#2 & 1.004 & 16.310 & 20.898 & 49.254 & 0.882 & 0.040 & 3.971 & 7.641 & 79.2 & 72.3 \\
\hline FACE J\#2 & 10.798 & 27.223 & 0.606 & 32.512 & 1.117 & 24.270 & 2.752 & 0.721 & 76.3 & 75.8 \\
\hline
\end{tabular}

" The RON and MON are calculated using the method of Ghosh et al. [78]. 

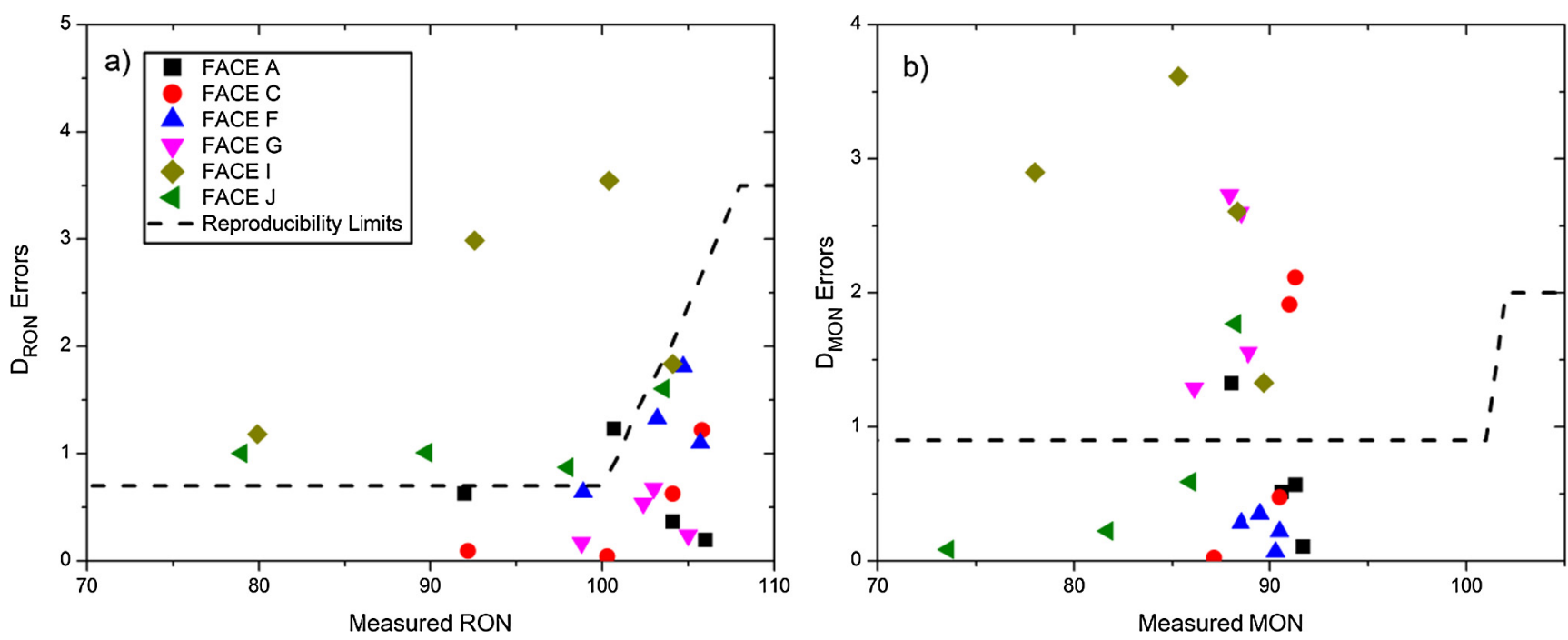

Fig. 9. Predicted (a) $D_{\text {RON }}$ and (b) $D_{\text {MON }}$ errors versus measured RONs and MONs for FACE surrogates \#2/ethanol blends using the developed model.

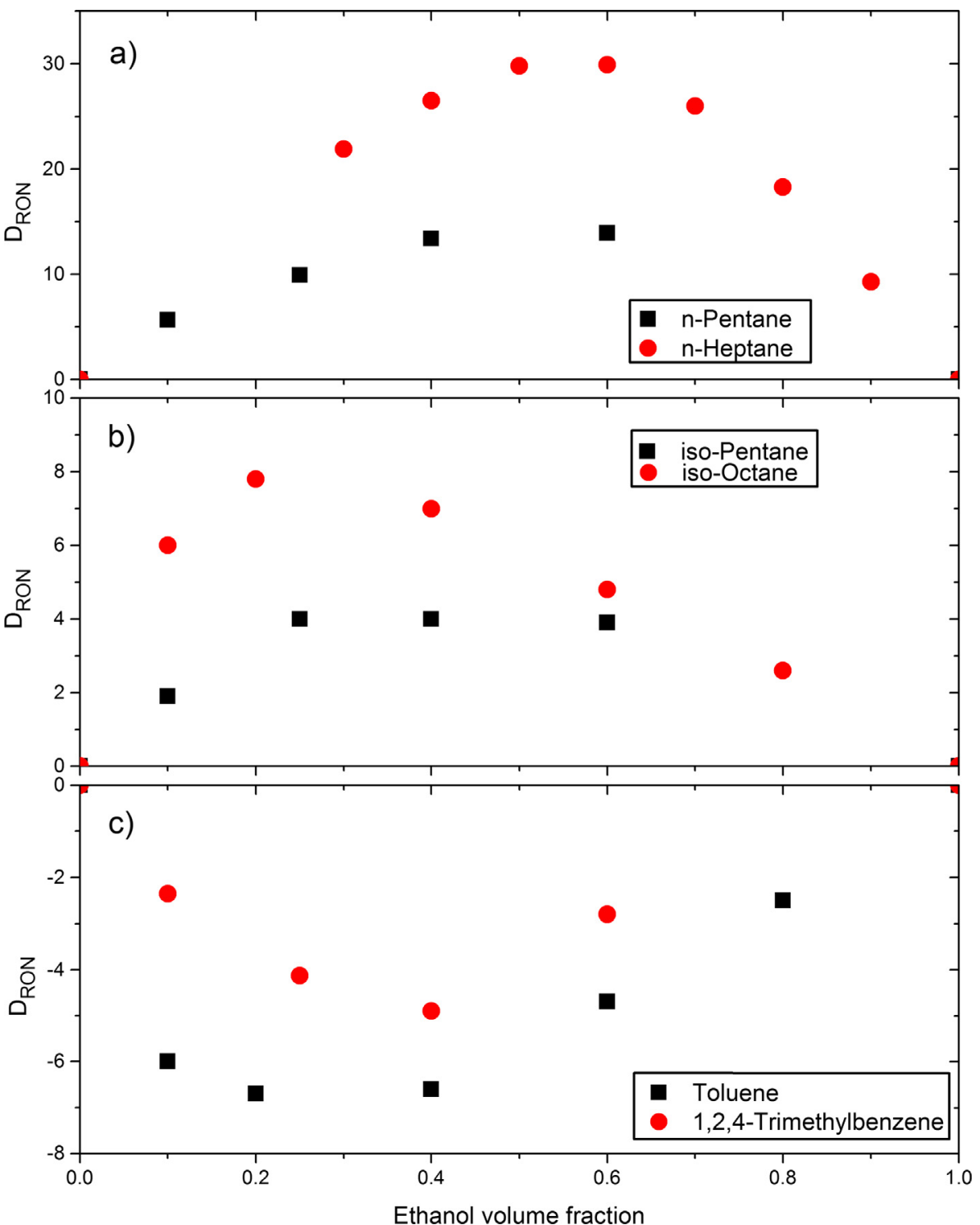

Fig. 10. $D_{\text {RON }}$ versus ethanol volume fraction for (a) n-paraffins, (b) iso-paraffins and (c) aromatics studied in this work. 


\section{Discussion and analysis}

The developed model is provided in Supplementary material as an excel sheet to facilitate the calculation of the octane numbers of any surrogate containing the 8 studied components blended with ethanol. The model can also be utilized via a web-interface on CloudFlame (cloudflame.kaust.edu.sa) [79]. The inputs to the ON predictions are the volume percentages of the 8 components in the base surrogate fuel, the RON and MON of the base mixture and the ethanol volume fraction added to the blend. In general, the proposed model accurately predicts the $D_{\text {RON }}$ and $D_{\text {MON }}$ of gasoline multi-component surrogates blends with ethanol. The proposed model and the methodologies of formulating the FACE surrogates are possible causes of predicted $D_{\mathrm{ON}}$ errors of FACE gasoline fuels/ethanol blends ON that are outside the acceptable limits. One possible way of improving the model is to include more scaling factors to account for the interactions between the various tested components. It was also shown that the volume based D values, especially for n-heptane/ethanol blends, are significantly larger than those of the mole based ones. $\mathrm{D}$ is a critical parameter in the presented model, and further comparisons against a mole based model would be useful. However, despite the different compositions of the FACE surrogates, the predicted $D_{\mathrm{ON}}$ errors are encouraging and mostly within the reproducibility limits when considering the 8 available species. In fact, only 16\%, 20\%, $12 \%$ and $8 \%$ of the $D_{\text {RON }}$ errors are more than $2 D_{\text {RON }}$ for TPRF surrogates, surrogates \#1, PIONA surrogates and surrogates \#2, respectively. Similarly, $25 \%, 20 \%, 20 \%$ and $25 \%$ of the $\mathrm{D}_{\mathrm{MON}}$ errors are more than $2 \mathrm{D}_{\mathrm{MON}}$ for TPRF surrogates, surrogates \#1, PIONA surrogates and surrogates \#2, respectively. Comparing the predictions of the four surrogates reveals that FACE PIONA surrogates and surrogates \#2 result in better predictions than surrogates \#1 and TPRF surrogates. This suggests that matching the PIONA of the base FACE gasolines is critical to the accuracy of the predictions. This is expected from the observed synergistic and antagonistic effects of different pure components with the addition of ethanol.

To further elaborate on this, these synergistic and antagonistic effects are compared for the n-paraffinic, iso-paraffinic and aromatics components studied in this work. $D_{\text {RON }}$ for the studied $\mathrm{n}$-paraffins (n-pentane and n-heptane), iso-paraffins (iso-pentane and iso-octane) and aromatics (toluene and 1,2,4trimethylbenzene) are presented in Fig. 10 against the ethanol volume fractions. It is clearly seen that the length of the n-paraffinic carbon chain affects the synergistic effect when blended with ethanol. n-Heptane has higher $D_{\text {RON }}$ values than n-pentane, as shown in Fig. 10a. The same is observed for iso-paraffins wherein iso-octane has higher synergistic effect than iso-pentane (Fig. 10b). Regarding aromatics, Fig. 10c demonstrates that the addition of two more methyl $\left(\mathrm{CH}_{3}\right)$ groups to the benzene ring decreases the antagonistic effects of aromatics/ethanol blends. These findings are critical for the explanation of these synergistic and antagonistic effects and what chemical kinetic roots are causing them. These findings are useful for the optimization of the octane response due to the addition of ethanol to gasoline surrogates. A possible way to improve the octane response per unit addition of ethanol is to reduce the aromatics contents in the base fuel because they generally have antagonistic effects when blended with ethanol. It was shown that a reduction in aromatics facilitates energy and cost savings in gasoline base stock production and enables meeting gasoline pump octane requirement with ethanol addition [80]. Additional costs and energy consumption and poorer fuel economy are possible effects if more ethanol is required to compensate for the decrease in ON due to the reduction of aromatics. In addition, the utilization of longer chain n-paraffins and iso-paraffins improves the octane response with ethanol blends as can be seen from the $\mathrm{D}$ values presented below. Finally, the presence of additional methyl $\left(\mathrm{CH}_{3}\right)$ substitutions to the aromatic ring improves the octane response as well. In summary, the octane response due to the addition of ethanol is proportional to the synergistic addition or antagonistic subtraction from the linear line induced by the various base fuel components, and the present analysis enables an optimization of the base fuel composition to maximize the octane number of gasoline/ethanol mixtures.

\section{Conclusions}

New RON and MON experimental data were measured for five additional pure components and six FACE gasoline fuels with ethanol. These pure components were carefully chosen to cover the classes of molecules relevant to gasoline fuels. A relatively simple volume based blending rule to predict the octane ratings of PRFs, TPRFs and multi-component/ethanol blends was developed in this study. Experimental data from Saudi Aramco's CFR engine and from literature were used to determine the parameters needed for the model. The developed model was based on the pure components synergistic and antagonistic effects when blended with ethanol as well as the introduction of scaling factors to account for the cross-reactions between the different molecules when mixed with ethanol. The model was extended to cover all the studied components and was validated against numerous blends of PRFs/ethanol, TPRFs/ethanol and FACE gasoline fuels/ ethanol blends. The predictions were mostly within the experimental reproducibility limits. The proposed model is also applicable for a wide range of ON. Finally, some insights into the variations of the synergistic and antagonistic effects of the studied components with ethanol were provided.

\section{Acknowledgements}

This work was sponsored by the Fuel Technology Division at Saudi Aramco R\&DC. The work at King Abdullah University of Science and Technology (KAUST) was supported by KAUST under the Clean Combustion Research Center's Future Fuels program and Saudi Aramco under FUELCOM.

\section{Appendix A. Supplementary material}

Supplementary data associated with this article can be found, in the online version, at http://dx.doi.org/10.1016/j.apenergy.2017. 06.084.

\section{References}

[1] Yan J, Lin T. Biofuels in Asia. Appl Energy 2009;86:S1-S10.

[2] Turner JWG, Pearson RJ, Dekker E, Iosefa B, Johansson K, ac Bergström K. Extending the role of alcohols as transport fuels using iso-stoichiometric ternary blends of gasoline, ethanol and methanol. Appl Energy 2013:102:72-86

[3] Anderson JE, DiCicco DM, Ginder JM, Kramer U, Leone TG, Raney-Pablo HE, et al. High octane number ethanol-gasoline blends: Quantifying the potential benefits in the United States. Fuel 2012;97:585-94.

[4] Leone TG, Anderson JE, Davis RS, Iqbal A, Reese RA, Shelby MH, et al. The effect of compression ratio, fuel octane rating, and ethanol content on spark-ignition engine efficiency. Environ Sci Technol 2015;49:10778-89.

[5] Muranaka S, Takagi Y, Ishida T. Factors limiting the improvement in thermal efficiency of S. I. engine at higher compression ratio. SAE International, SAE Technical Paper 870548; 1987.

[6] Milpied J, Jeuland N, Plassat G, Guichaous S, Dioc N, Marchal A et al. Impact of fuel properties on the performances and knock behaviour of a downsized turbocharged DI SI engine-focus on octane numbers and latent heat of vaporization. SAE Int J Fuels Lubr 2009;2:118-26.

[7] Stein RA, House CJ, Leone TG. Optimal use of E85 in a turbocharged direct injection engine. SAE Int J Fuels Lubr 2009;2:670-82. 
[8] Costagliola MA, De Simio L, Iannaccone S, Prati MV. Combustion efficiency and engine out emissions of a S.I. engine fueled with alcohol/gasoline blends. Appl Energy 2013;111:1162-71.

[9] Chang J, Viollet Y, Alzubail A, Abdul-Manan AFN, Al Arfaj A. Octane-on-demand as an enabler for highly efficient spark ignition engines and greenhouse gas emissions improvement. SAE International, SAE Technical Paper 2015-01$1264 ; 2015$.

[10] Morganti K, Alzubail A, Abdullah M, Viollet Y, Head R, Chang J, et al. Improving the efficiency of conventional spark-ignition engines using octane-on-demand combustion - Part II: vehicle studies and life cycle assessment. SAE International, SAE Technical Paper 2016-01-0683; 2016.

[11] Viollet Y, Abdullah M, Alhajhouje A, Chang J. Characterization of high efficiency octane-on-demand fuels requirement in a modern spark ignition engine with dual injection system. SAE International, SAE Technical Paper 2015-01-1265; 2015.

[12] Cho J, Si W, Jang W, Jin D, Myung C-L, Park S. Impact of intermediate ethanol blends on particulate matter emission from a spark ignition direct injection (SIDI) engine. Appl Energy 2015;160:592-602.

[13] Wu H-W, Wang R-H, Ou D-J, Chen Y-C, Chen T-y. Reduction of smoke and nitrogen oxides of a partial HCCI engine using premixed gasoline and ethanol with air. Appl Energy 2011;88:3882-90.

[14] Iodice P, Senatore A, Langella G, Amoresano A. Effect of ethanol-gasoline blends on $\mathrm{CO}$ and $\mathrm{HC}$ emissions in last generation SI engines within the coldstart transient: An experimental investigation. Appl Energy 2016;179:182-90.

[15] Energy Independence and Security Act of 2007. Public law; 2007. p. 110-40.

[16] EU. Directive 2009/28/EC of The European Parliament and of The Council of 23 April 2009 on the promotion of the use of energy from renewable sources and amending and subsequently repealing Directives 2001/77/EC and 2003/30/EC. Off J European Union; 2009. p. 16-62.

[17] Von Blottnitz H. Curran MA. A review of assessments conducted on bioethanol as a transportation fuel from a net energy, greenhouse gas, and environmental life cycle perspective. J Clean Prod 2007;15:607-19.

[18] Celik MB. Experimental determination of suitable ethanol-gasoline blend rate at high compression ratio for gasoline engine. Appl Therm Eng 2008;28:396-404.

[19] Daniel R, Wang C, Xu H, Tian G, Richardson D. Dual-injection as a knock mitigation strategy using pure ethanol and methanol. SAE Int J Fuels Lubr 2012;5:772-84.

[20] Hernandez M, Menchaca L, Mendoza A. Fuel economy and emissions of lightduty vehicles fueled with ethanol-gasoline blends in a Mexican City. Renew Energy 2014;72:236-42.

[21] Kikuchi R, Gerardo R, Santos SM. Energy lifecycle assessment and environmental impacts of ethanol biofuel. Int J Energy Res 2009;33:186-93.

[22] Nakata K, Utsumi S, Ota A, Kawatake K, Kawai T, Tsunooka T. The effect of ethanol fuel on a spark ignition engine. SAE Technical Paper; 2006.

[23] MacLean HL, Lave LB, Lankey R, Joshi S. A life-cycle comparison of alternative automobile fuels. J Air Waste Manag Assoc 2000;50:1769-79.

[24] Speth RL, Chow EW, Malina R, Barrett SR, Heywood JB, Green WH. Economic and environmental benefits of higher-octane gasoline. Environ Sci Technol 2014;48:6561-8.

[25] Spatari S, Zhang Y, MacLean HL. Life cycle assessment of switchgrass-and corn stover-derived ethanol-fueled automobiles. Environ Sci Technol 2005;39:9750-8.

[26] Amer A, Babiker H, Chang J, Kalghatgi G, Adomeit P, Brassat A, et al. Fuel effects on knock in a highly boosted direct injection spark ignition engine. SAE Int J Fuels Lubr 2012;5:1048-65.

[27] Anderson J, Kramer U, Mueller S, Wallington T. Octane numbers of ethanoland methanol- gasoline blends estimated from molar concentrations. Energy Fuels 2010;24:6576-85.

[28] Leone TG, Olin ED, Anderson JE, Jung HH, Shelby MH, Stein RA. Effects of fuel octane rating and ethanol content on knock, fuel economy, and $\mathrm{CO}_{2}$ for a turbocharged DI engine. SAE Int J Fuels Lubr 2014;7:9-28.

[29] Balat M, Balat H. Recent trends in global production and utilization of bioethanol fuel. Appl Energy 2009;86:2273-82.

[30] Pimentel D, Patzek TW. Ethanol production using corn, switchgrass, and wood; biodiesel production using soybean and sunflower. Nat Resour Res 2005; $14: 65-76$.

[31] Moreira JR, Romeiro V, Fuss S, Kraxner F, Pacca SA. BECCS potential in Brazil: achieving negative emissions in ethanol and electricity production based on sugar cane bagasse and other residues. Appl Energy 2016;179:55-63.

[32] Khatiwada D, Venkata BK, Silveira S, Johnson FX. Energy and GHG balances of ethanol production from cane molasses in Indonesia. Appl Energy 2016;164:756-68.

[33] Nguyen TLT, Hermansen JE. System expansion for handling co-products in LCA of sugar cane bio-energy systems: GHG consequences of using molasses for ethanol production. Appl Energy 2012;89:254-61.

[34] Chiaramonti D, Lidén G, Yan J. Advances in sustainable biofuel production and use. Appl Energy 2013;102:1-4.

[35] Da Silva R, Cataluna R, de Menezes EW, Samios D, Piatnicki CMS. Effect of additives on the antiknock properties and Reid vapor pressure of gasoline. Fuel 2005;84:951-9.

[36] Han J, Elgowainy A, Wang M, Divita V. Well-to-wheels greenhouse gas emissions analysis of high-octane fuels with various market shares and ethanol blending levels. Argonne National Lab. (ANL), Argonne, IL (United States); 2015.
[37] Sarathy SM, Oßwald P, Hansen N, Kohse-Höinghaus K. Alcohol combustion chemistry. Prog Energy Combust Sci 2014;44:40-102.

[38] AlRamadan AS, Badra J, Javed T, Al-Abbad M, Bokhumseen N, Gaillard P, et al. Mixed butanols addition to gasoline surrogates: Shock tube ignition delay time measurements and chemical kinetic modeling. Combust Flame 2015;162:3971-9.

[39] Heywood JB. Internal combustion engine fundamentals. New York: Mcgrawhill; 1988.

[40] Stone R. Introduction to internal combustion engines. Palgrave Macmillan; 2012.

[41] Kalghatgi G. Fuel/engine interactions. Warrendale, PA: SAE International; 2013.

[42] Standard test method for research octane number of spark-ignition engine fuel. ASTM D 2699 - 13b; 2013.

[43] Standard test method for motor octane number of spark-ignition engine fuel. ASTM D 2700-14; 2014

[44] AlRamadan AS, Sarathy SM, Khurshid M, Badra J. A blending rule for octane numbers of PRFs and TPRFs with ethanol. Fuel 2016;180:175-86.

[45] Yuan H, Yang Y, Brear MJ, Foong TM, Anderson JE. Optimal octane number correlations for mixtures of toluene reference fuels (TRFs) and ethanol. Fuel 2017;188:408-17.

[46] Hunwartzen I. Modification of CFR test engine unit to determine octane numbers of pure alcohols and gasoline-alcohol blends. SAE International, SAE Technical Paper 820002; 1982.

[47] API. Determination of the potential property ranges of mid-level ethanol blends; 2010.

[48] Anderson JE, Leone TG, Shelby MH, Wallington TJ, Bizub JJ, Foster M, et al. Octane numbers of ethanol-gasoline blends: measurements and novel estimation method from molar composition. SAE International, SAE Technical Paper 2012-01-1274; 2012.

[49] Foong TM, Morganti KJ, Brear MJ, da Silva G, Yang Y, Dryer FL. The octane numbers of ethanol blended with gasoline and its surrogates. Fue 2014;115:727-39.

[50] Solaka Aronsson H, Tuner M, Johansson B. Using oxygenated gasoline surrogate compositions to map RON and MON. SAE International, SAE Technical Paper 2014-01-1303; 2014.

[51] Cannella W, Foster M, Gunter G, Leppard W. FACE gasolines and blends with ethanol: detailed characterization of physical and chemical properties. 3650 MANSELL ROAD SUITE 140 ALPHARETTA, GA 30022: COORDINATING RESEARCH COUNCIL, INC.; 2014.

[52] Sarathy SM, Kukkadapu G, Mehl M, Javed T, Ahmed A, Naser N, et al Compositional effects on the ignition of FACE gasolines. Combust Flame 2016;169:171-93.

[53] Chen B, Togbé C, Wang Z, Dagaut P, Sarathy SM. Jet-stirred reactor oxidation of alkane-rich FACE gasoline fuels. Proc Combust Inst 2017;36:517-24.

[54] Sarathy SM, Kukkadapu G, Mehl M, Wang W, Javed T, Park S, et al. Ignition of alkane-rich FACE gasoline fuels and their surrogate mixtures. Proc Combust Inst 2015;35:249-57.

[55] Selim H, Mohamed SY, Dawood AE, Sarathy SM. Understanding premixed flame chemistry of gasoline fuels by comparing quantities of interest. Proc Combust Inst 2017;36:1203-11.

[56] Javed T, Nasir EF, Es-sebbar E-t, Farooq A. A comparative study of the oxidation characteristics of two gasoline fuels and an n-heptane/iso-octane surrogate mixture. Fuel 2015;140:201-8.

[57] Bhavani Shankar VS, Sajid M, Al-Qurashi K, Atef N, Alkhesho I, Ahmed A, et al Primary reference fuels (PRFs) as surrogates for low sensitivity gasoline fuels SAE International, SAE Technical Paper 2016-01-0748; 2016.

[58] Ahmed A, Waqas M, Naser N, Singh E, Roberts W, Chung S, et al. Compositiona effects of gasoline fuels on combustion, performance and emissions in engine. SAE Int J Fuels Lubr 2016;9:460-8.

[59] Vallinayagam R, Vedharaj S, Roberts WL, Dibble RW, Sarathy SM. Performance and emissions of gasoline blended with terpineol as an octane booster. Renew Energy 2017; 101:1087-93.

[60] Bugler J, Marks B, Mathieu O, Archuleta R, Camou A, Grégoire C, et al. An ignition delay time and chemical kinetic modeling study of the pentane isomers. Combust Flame 2016;163:138-56.

[61] Bugler J, Somers KP, Silke EJ, Curran HJ. Revisiting the kinetics and thermodynamics of the low-temperature oxidation pathways of alkanes: a case study of the three pentane isomers. J Phys Chem A 2015;119:7510-27.

[62] Zhang K, Banyon C, Bugler J, Curran HJ, Rodriguez A, Herbinet O, et al. An updated experimental and kinetic modeling study of n-heptane oxidation. Combust Flame 2016:172:116-35.

[63] Atef N, Kukkadapu G, Mohamed SY, Rashidi MA, Banyon C, Mehl M, et al. A comprehensive iso-octane combustion model with improved thermochemistry and chemical kinetics. Combust Flame 2017;178:111-34.

[64] Zhang Y, Somers KP, Mehl M, Pitz WJ, Cracknell RF, Curran HJ. Probing the antagonistic effect of toluene as a component in surrogate fuel models at low temperatures and high pressures. A case study of toluene/dimethyl ether mixtures. Proc Combust Inst 2017:36:413-21.

[65] Al Rashidi MJ, Thion S, Togbé C, Dayma G, Mehl M, Dagaut P, et al. Elucidating reactivity regimes in cyclopentane oxidation: Jet stirred reactor experiments, computational chemistry, and kinetic modeling. Proc Combust Inst 2017;36:469-77.

[66] Rashidi MJA, Calero J, Banyon C, Sajid MB, Mehl M, Pitz WJ, et al. Cyclopentane combustion. Part II. Experimental ignition delay measurements and 
mechanism validation. Combust Flame 2017. http://dx.doi.org/10.1016/ j.combustflame.2017.05.017.

[67] Rashidi MJA, Zádor J, Mehl M, Pitz WJ, Sarathy SM. Cyclopentane combustion. Part 1. Mechanism development and computational kinetics. Combust Flame 2017. http://dx.doi.org/10.1016/i.combustflame.2017.05.018.

[68] Mehl M, Pitz WJ, Westbrook CK, Curran HJ. Kinetic modeling of gasoline surrogate components and mixtures under engine conditions. Proc Combust Inst 2011;33:193-200.

[69] Mehl M, Vanhove G, Pitz WJ, Ranzi E. Oxidation and combustion of the nhexene isomers: a wide range kinetic modeling study. Combust Flame 2008; $155: 756-72$.

[70] Determination of knock characteristics (octane number) of alcohols and alcohol/fuel mixtures using the CFR engine. DIN 51756-7: Deutsches Institut für Normung; 1986.

[71] Badra J, Elwardany A, Sim J, Viollet Y, Im H, Chang J. Effects of in-cylinder mixing on low octane gasoline compression ignition combustion. SAE International, SAE Technical Paper 2016-01-0762; 2016.

[72] Badra J, Viollet Y, Elwardany A, Im HG, Chang J. Physical and chemical effects of low octane gasoline fuels on compression ignition combustion. Appl Energy 2016;183:1197-208.
[73] Badra JA, Bokhumseen N, Mulla N, Sarathy SM, Farooq A, Kalghatgi G, et al. A methodology to relate octane numbers of binary and ternary n-heptane, isooctane and toluene mixtures with simulated ignition delay times. Fuel 2015;160:458-69.

[74] Badra JA, Sim J, Elwardany A, Jaasim M, Viollet Y, Chang J, et al. Numerical simulations of hollow-cone injection and gasoline compression ignition combustion with naphtha fuels. J Energy Resour Technol 2016;138. 052202052202.

[75] Javed T, Lee C, AlAbbad M, Djebbi K, Beshir M, Badra J, et al. Ignition studies of n-heptane/iso-octane/toluene blends. Combust Flame 2016;171:223-33.

[76] Kalghatgi G, Babiker H, Badra J. A simple method to predict knock using toluene, $\mathrm{N}$-heptane and iso-octane blends (TPRF) as gasoline surrogates. SAE Int J Engines 2015;8:505-19.

[77] Andrae JCG, Head RA. HCCI experiments with gasoline surrogate fuels modeled by a semidetailed chemical kinetic model. Combust Flame 2009:156:842-51.

[78] Ghosh P, Hickey KJ, Jaffe SB. Development of a detailed gasoline compositionbased octane model. Ind Eng Chem Res 2006;45:337-45.

[79] Reyno-Chiasson Z, Nettyam N, Goteng GL, Speight M, Lee BJ, Baskaran S, et al. CloudFlame and PrIMe: accelerating combustion research in the cloud; 2015.

[80] Zhang B, Sarathy SM. Lifecycle optimized ethanol-gasoline blends for turbocharged engines. Appl Energy 2016;181:38-53. 